\title{
Cardiovascular Dementia - A Different Perspective
}

\author{
Udhaya Kumari and Klaus Heese*
}

Division of Cell and Molecular Biology, School of Biological Sciences, College of Science, Nanyang Technological University, 60 Nanyang Drive, Singapore 637551

\begin{abstract}
The number of dementia patients has been growing in recent years and dementia represents a significant threat to aging people all over the world. Recent research has shown that the number of people affected by Alzheimer's disease (AD) and dementia is growing at an epidemic pace. The rapidly increasing financial and personal costs will affect the world's economies, health care systems, and many families. Researchers are now exploring a possible connection among $\mathrm{AD}$, vascular dementia (VD), diabetes mellitus (type 2, T2DM) and cardiovascular diseases (CD). This correlation may be due to a strong association of cardiovascular risk factors with $\mathrm{AD}$ and VD, suggesting that these diseases share some biologic pathways. Since heart failure is associated with an increased risk of AD and VD, keeping the heart healthy may prove to keep the brain healthy as well. The risk for dementia is especially high when diabetes mellitus is comorbid with severe systolic hypertension or heart disease. In addition, the degree of coronary artery disease (CAD) is independently associated with cardinal neuropathological lesions of AD. Thus, the contribution of T2DM and CD to AD and VD implies that cardiovascular therapies may prove useful in preventing $\mathrm{AD}$ and dementia.
\end{abstract}

Keywords: Alzheimer's disease, Cardiovascular disease, Heart, Kidney, NGF, Vascular dementia.

\section{INTRODUCTION}

Recent epidemiologic and clinico-pathologic data suggest overlaps between $\mathrm{AD}$ and cerebrovascular lesions that may magnify the effect of mild AD pathology. This interaction may promote the progression of cognitive decline or even precede neuronal damage and dementia. Vascular pathology in the aging brain and in $\mathrm{AD}$ includes cerebral amyloid angiopathy (CAA), multiple or recurrent microhaemorrhages and ischaemic infarcts. AD cases with additional minor cerebrovascular lesions are much more likely to have a history of hypertension or infarcts than "pure" AD patients. There is a documented association of low plasma amyloid-beta peptide ratios (A $\beta 42 / \mathrm{A} \beta 40)$ with increased imminent risk for mild cognitive impairment and $A D$ [1]. The observation that the nerve growth factor receptor (NGFR, also known as neurotrophic tyrosine kinase receptor 1 (NTRK1) or TRKA) is down-regulated in AD brains led to the suggestion that an imbalance in NGF/NTRK1 signalling might be involved in AD [2-4]. Heart-derived NGF also regulates the survival and maintenance of sympathetic neurons that innervate the heart and is a crucial factor in myocardial ischaemia, a main cause of sudden death in diabetes mellitus [5]. Thus, researchers are currently exploring the possibility of a connection among $\mathrm{AD}, \mathrm{VD}, \mathrm{T} 2 \mathrm{DM}$ and $\mathrm{CD}[6,7]$. The risk for dementia is especially high when T2DM occurs together with severe systolic hypertension or heart disease. In addition, the degree of $\mathrm{CAD}$ is independently associated with the cardinal neuropathological lesions of $\mathrm{AD}$ [8]. Consequently, the association of heart failure with an increased risk of $\mathrm{AD}$ and

*Address correspondence to this author at the Department of Molecular and Cell Biology, School of Biological Sciences, College of Science, Nanyang Technological University, 60 Nanyang Drive, Singapore 637551; Tel: +656316-2848; Fax: +65-6791-3856; E-mail: kheese@ntu.edu.sg
VD suggests that the general advice to keep the heart healthy may prove to keep the brain healthy as well [9]. The strong association of cardiovascular risk factors with $\mathrm{AD}$ and $\mathrm{VD}$ suggests that these diseases share some biologic pathways. The contribution of cardiovascular disease to AD and VD implies that cardiovascular therapies may prove useful for the treatment or prevention of $\mathrm{AD}$ and dementia [10-13]. Since NGF has also been discussed as a crucial molecule in diabetic nephropathy [14], it is considered a potential biomarker for $\mathrm{AD}$ and neuro-immune diseases [15-17]. This review intends to unravel some potential links among various diseases including $\mathrm{AD}, \mathrm{VD}, \mathrm{T} 2 \mathrm{DM}$ and $\mathrm{CD}$.

\section{ALZHEIMER'S DISEASE}

$\mathrm{AD}$ is a progressive neurodegenerative disorder that is characterised by two types of proteinaceous deposits in the brain: extracellular amyloid plaques and intracellular neurofibrillary tangles (NFTs). The term "Alzheimer's disease" was coined after the name of its discoverer, Alois Alzheimer, a German neuropathologist who first described the symptoms of this disease in a 51-year-old patient named "Auguste". $\mathrm{AD}$ is a specific neurodegenerative disease and remains the most common cause of dementia among the elderly. Today, approximately 37 million people worldwide suffer from diverse forms of dementia, and about 18 million of them have AD [18]. The number of patients afflicted with $\mathrm{AD}$ is expected to rise and double by the year 2025. AD disrupts communication between brain regions by causing neurons to lose functionality and die [19]. Common symptoms of $\mathrm{AD}$ include progressive loss of memory and cognitive dysfunctions such as language deterioration, impaired visuospatial skills, poor judgement, inability to learn new things, indifference, depression, delusions and other manifestations [20]. AD primarily affects the cerebral cortex (grey matter) of the temporal lobe (involved in memory, auditory stimuli and speech), the parietal lobe 
(involved in orientation, recognition and perception of stimuli) and the frontal lobe (used for reasoning judgment, emotions, movement and speech) of the brain. Deeper structures of the brain, such as the hippocampus (involved in memory and learning processes), and the amygdala (involved in emotional drives), are also affected in AD [21].

AD is classified into two subsets: early onset familial AD (FAD) and late onset sporadic AD (SAD). FAD is very rare and has been found in relatively small numbers of families [22]. Three genes account for the less prevalent FAD: presenilin1 (PS1), PS2 and the amyloid precursor protein (APP) [23]. Mutations in the APP gene, which is located on chromosome 21 , have been postulated to play a major role in the aggregation of a clumped sticky protein fragment known as A $\beta$ [24]. The PS1 and PS2 genes are located on chromosomes 14 and 1, respectively. Mutations in the PS1 gene causes enhanced proteolytic processing of APP and lead to the most aggressive form of FAD. Evidence from rodent studies suggests that PS1 mutation results in impaired hippocampus-dependent learning, which also correlates with reduced adult neurogenesis in the dentate gyrus [25].

$\mathrm{SAD}$ is the most prevalent form of the disease, affecting about $90 \%$ of AD patients. It affects people over the age of 65 , including around $50 \%$ of all people over the age of 85 . $\mathrm{SAD}$ is not caused by a specific gene mutation. The most studied gene in SAD is ApoE (polymorphic protein), which is responsible for the production of a protein involved in cholesterol and lipid transport. It exists in three forms, or alleles, named ApoE2, ApoE3, and ApoE4. The ApoE4 allele is a well-established risk factor for SAD [26].

Based on AD research over the past 50 years, three main hypotheses have been discussed. The oldest hypothesis is the "cholinergic hypothesis", which states that AD begins as a deficiency in the production of acetylcholine (ACh), a vital neurotransmitter [27]. Loss of cholinergic neurons is coupled specifically with typical clinical symptoms such as memory deficits, impaired attention, cognitive decline and reduced learning abilities. The other two hypotheses are called the "Tau-ist" hypothesis and the "ba-ptist" hypothesis. Due to the accumulation of abnormally folded $A \beta$ and Tau proteins in the brains of $\mathrm{AD}$ patients, $\mathrm{AD}$ has also been called a protein misfolding disease (proteopathy) [28].

Glucose is transported across the blood brain barrier (BBB) into the extracellular space through specific glucose transporters such as GLUT1. Glucose that enters the glycolytic pathway forms Acetyl-CoA. The memory enhancing and memory stabilising neurotransmitter ACh is produced from Acetyl-CoA and choline under the control of insulin. ACh can then bind to nicotinic and muscarinergic ACh receptors that are thus also targets for the treatment of $\mathrm{AD}$ [29-31]. In addition, the binding of $\mathrm{ACh}$ to its muscarinergic $\mathrm{m} 1$ and $\mathrm{m} 3$ receptors can then stimulate the formation of soluble APP (sAPP). sAPP in turn can then modulate synaptic plasticity in the hippocampus and promotes dendritic outgrowth [32].

The "Tau-ist" hypothesis revolves around the microtubule-associated protein Tau (MAPT) [33]. Healthy neurons have an internal cytoskeleton, partly made up of structures called microtubules. Microtubules play an important role in nutrient and neurotransmitter transport, structural integrity and cell regulation within neurons. They are mainly present in neuronal axons. The Tau protein helps to stabilise the microtubules through phosphorylation [34, 35]. However, in $\mathrm{AD}$ the Tau proteins become hyperphosphorylated and lose the ability to bind to microtubules. Instead, the hyperphosphorylated Tau proteins bind to each other and tie themselves into "knots" known as NFTs [36]. These NFTs destabilise microtubules and collapse the neuronal transport system. Hence, NFT formation results in malfunctions of the microtubulemediated transport system as well as in communication among neurons, eventually leading to apoptosis [37].

According to the "Ba-ptist" hypothesis, $A \beta$ deposits are the causal factor for the disease. This theory is gaining popularity among scientists because of the recently discovered impaired vascular and cerebrospinal fluid (CSF) transport of $\mathrm{A} \beta$ peptides out of the brain and the resulting increase in risk for senile plaque (SP) formation [38, 39]. SPs and NFTs are associated with a loss of neurons and synapses, brain atrophy and dilatation of the lateral ventricles (due to a loss of brain tissue) [40, 41].

APP is a type-I transmembrane protein that has an extracellular N-terminal domain and a short intracellular Cterminal domain. This protein is expressed in many cell types that include neurons in the central nervous system (CNS). APP undergoes non-amyloidogenic cleavage by the $\alpha$-secretase, releasing soluble $\operatorname{sAPP} \alpha$ (Fig. 1) [42]. The release of sAPP from neurons has been implicated in neurite outgrowth and serine protease inhibitor function [43]. A second cleavage by $\gamma$-secretase results in the extracellular secretion of small p3 peptides and the intracellular release of the cytoplasmic tail AICD (APP intracellular domain). Once released, AICD is thought to act as a transcriptional activator and to perform other signalling roles. In contrast, the amyloidogenic cleavage of APP is initiated by $\beta$-secretase cleavage, a $\beta$-site APP-cleaving enzyme (BACE) that releases soluble sAPP $\beta$ [44]. The second part of this pathogenic cleavage is mediated by the $\gamma$-secretase, generating a 40 amino acid amyloid peptide (A $\beta 40)$ that is soluble and innocuous or a 42 amino acid peptide (A $\beta 42)$ that clumps to form insoluble amyloid plaques. The nonamyloidogenic pathway probably occurs in the Golgi network and at the cell surface, whereas the amyloidogenic $\beta$-secretase pathway is initiated at the endoplasmic reticulum (ER) [45].

\section{DIABETES}

All living organisms need energy to function, and glucose is a potential energy source. The amount of glucose in the bloodstream is regulated by various hormones, the most important of which is insulin. Blood glucose levels are not constant; the level fluctuates depending on the body's daily needs and hormonal regulations. Under normal conditions, the glucose levels range between 70 and 110 $\mathrm{mg} / \mathrm{dl}$. The blood glucose level may rise for three reasons: diet, breakdown of glycogen or hepatic synthesis of glucose. For the human body to function properly, an optimum level of glucose must be maintained in the blood. Extreme fluctuation of the level of glucose in the blood leads to various consequential phenotypes. For instance, diabetes is a metabolic disorder that is categorised into two major 


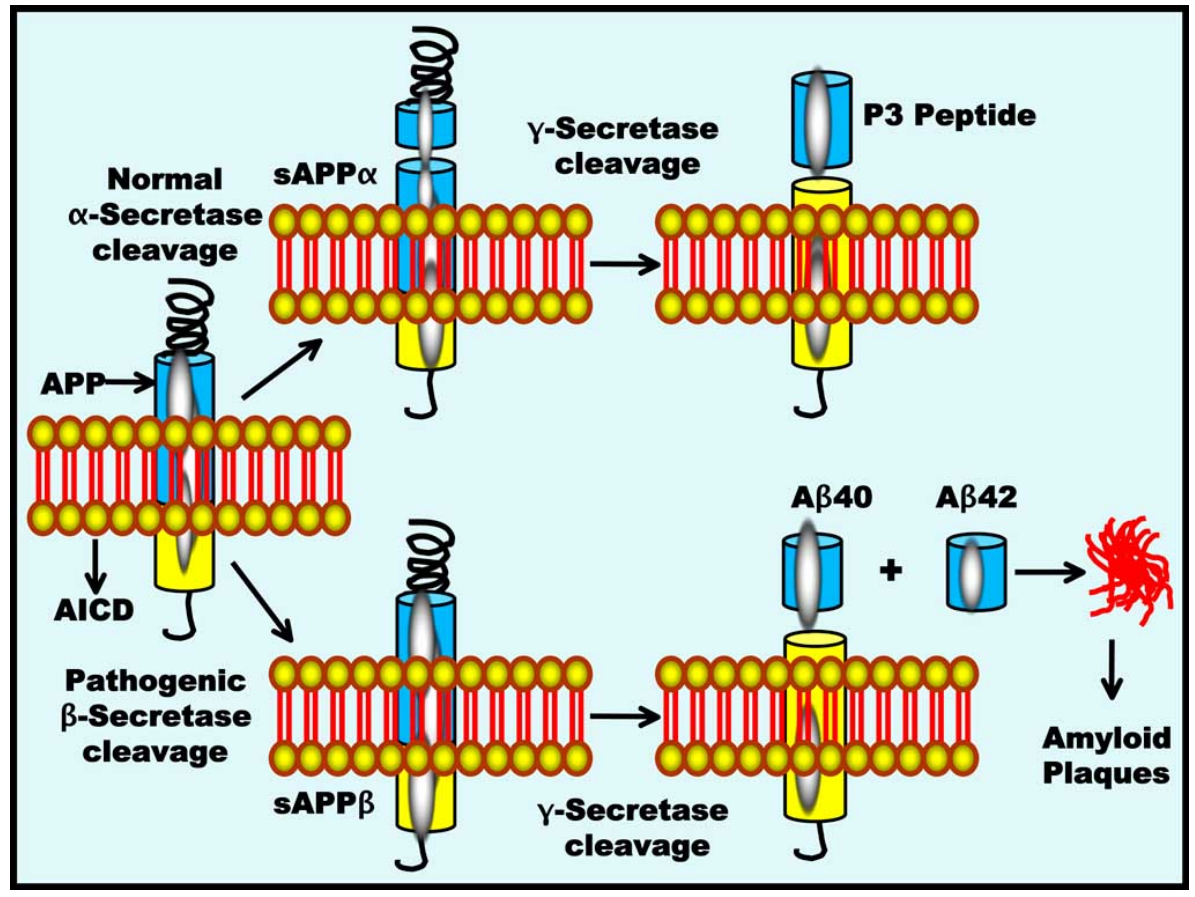

Fig. (1). APP processing and A $\beta$ accumulation. APP is metabolised by two competing pathways, the non-pathogenic $\alpha$-secretase pathway that generates sAPP $\alpha$ and the pathogenic $\beta$-secretase pathway that generates sAPP $\beta$. The $\alpha$-secretase and $\gamma$-secretase cleavage releases the p3 peptides, whereas pathogenic $\beta$-and $\gamma$-secretase cleavage gives rise to $A \beta 40$ and $A \beta 42$ peptide fragments. All carboxy-terminal fragments are substrates for $\gamma$-secretase, thus generating the APP intracellular domain (AICD) as well as the secreted peptides p3 and A $\beta$. A $\beta$ then aggregates into oligomers and subsequently into fibrillary amyloid plaques.

subgroups: type-1 diabetes mellitus (T1DM) and type-2 diabetes mellitus (T2DM). This classification is based on whether the elevation of blood glucose level is the result of insulin deficiency (T1DM) or insulin resistance (T2DM) [46]. T1DM is an autoimmune disease that occurs when low levels of insulin are produced by the pancreas due to a malfunction of insulin-producing beta cells. T1DM was previously termed "insulin-dependent diabetes mellitus" (IDDM), or juvenile-onset diabetes, and it accounts for $\sim 5$ $10 \%$ of all diagnosed cases of diabetes. This disorder is lethal unless treatment with an exogenous supply of insulin is used to replace this crucial hormone. T2DM, which was previously termed non-insulin dependent diabetes mellitus (NIDDM), or adult-onset diabetes, accounts for about 90$95 \%$ of all diagnosed cases [47, 48]. In T2DM, the pancreas functions normally to produce enough insulin but the cells of the body are resistant to it. T2DM is caused by insulin resistance in peripheral tissues and is most frequently associated with aging, a family history of diabetes, obesity and failure to exercise. Individuals with T2DM have hyperglycaemia and hyperinsulinaemia $[49,50]$.

\section{GLUCOSE TRIGGERS INSULIN SYNTHESIS AND SIGNALLING}

Insulin is a powerful anabolic and anti-catabolic peptide secreted exclusively by beta cells in the islets of Langerhans. These cells accumulate in tiny groups scattered throughout the tissue of the pancreas. Insulin is composed of two chains of amino acids (aa): the 21 aa A chain and the 30 aa B chain. Both chains are linked together by two disulfide bridges. However, a third disulfide bridge exists within the A-chain, linking the $6^{\text {th }}$ and $11^{\text {th }}$ residues of the A-chain. Insulin action is mediated by the IR, a complex multi-subunit cell surface glycoprotein. Binding of insulin activates the intrinsic tyrosine kinase activity of the receptor, which is composed of a pair of $\alpha$-subunits and a pair of $\beta$-subunits. These are distributed mainly in the cortex and hippocampus. Insulin binds to the $\alpha$-subunits and induces conformational changes that are transmitted to the $\beta$-subunits. Subsequently, the $\beta$ subunits autophosphorylate and initiate a cascade of phosphorylation and dephosphorylation reactions [51, 52].

Glucose is transported into beta cells by GLUT2 (Type 2 glucose transporters); it then undergoes the universal energyproducing pathway (glycolytic pathway) and enters the respiratory cycle. This produces the high energy ATP molecule via oxidation in the mitochondria. The increase in the ATP:ADP ratio also increases the number of ATP-gated potassium channels $\left(\mathrm{K}^{+}\right)$in the beta cell membrane, preventing $\mathrm{K}^{+}$ions from being shunted across the cell membrane (Fig. 2) [53]. The ensuing rise in positive charge inside the cell, due to increased concentration of $\mathrm{K}^{+}$ions, leads to a depolarisation of the cell. The net effect is the activation of voltage-gated calcium channels $\left(\mathrm{Ca}^{2+}\right)$, which transport calcium ions into the cell [54]. The brisk increase in intracellular $\mathrm{Ca}^{2+}$ level causes the activation of phospholipase C (PLC), which cleaves membrane phospholipid phosphatidylinositol-4,5-biphosphate (PIP2) into inositol-1,4,5-triphosphate (IP3) and diacylglycerol (DAG). IP3 then binds to 'receptor proteins' in the membrane of the ER. This triggers a rise in the concentration of $\mathrm{Ca}^{2+}$ in the cells and the subsequent activation (together with DAG) of protein kinase $\mathrm{C}$ (PKC) and finally the release of pre-synthesised insulin, which is stored in secretory vesicles. The $\mathrm{Ca}^{2+}$ level also regulates the expression of the insulin gene via the cAMP response element binding protein 


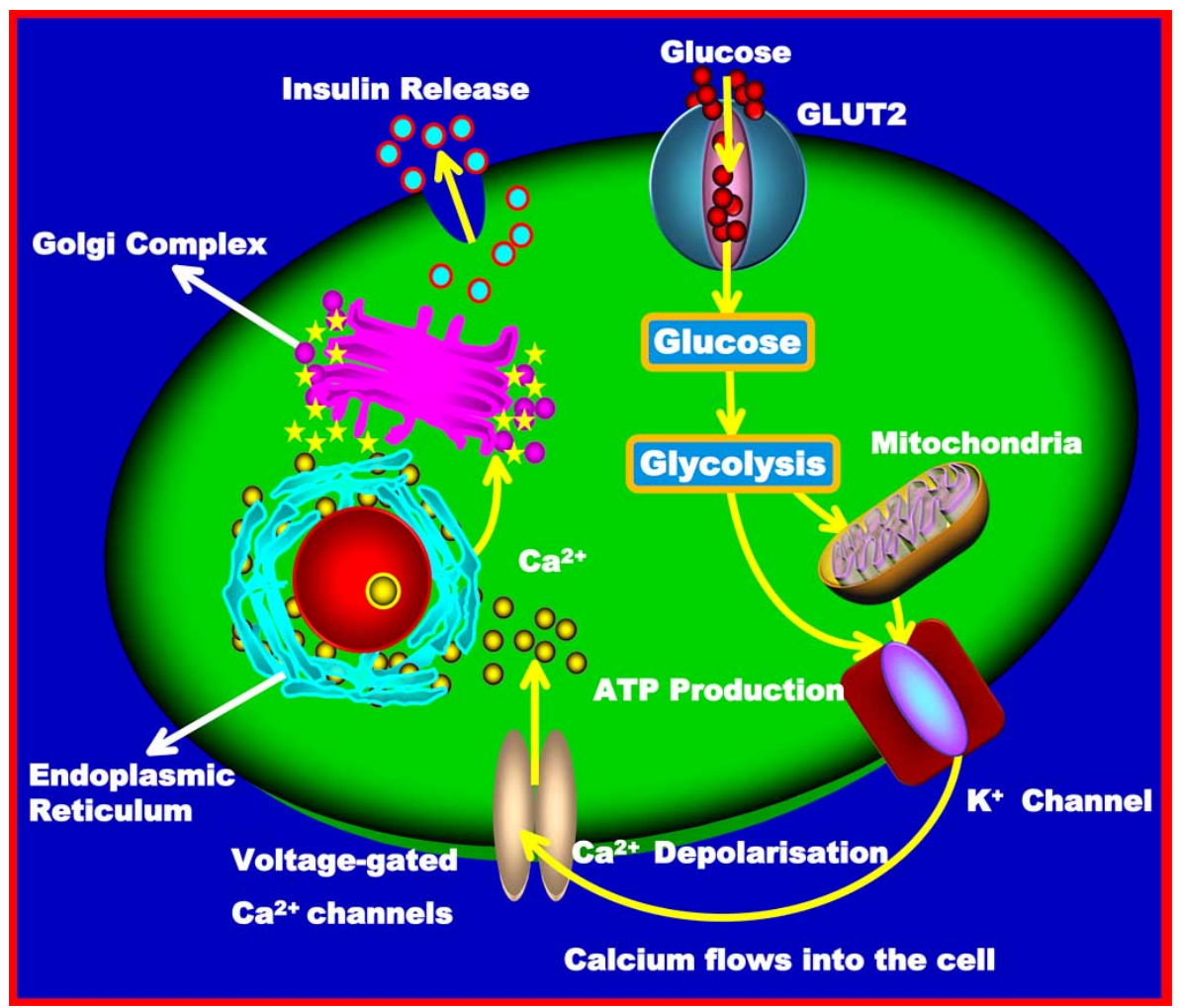

Fig. (2). Glucose triggers insulin synthesis and signalling. Insulin secretion in beta cells is triggered by rising blood glucose levels. Starting with the uptake of glucose by the GLUT2 transporter, the glycolytic phosphorylation of glucose causes an increase in the ATP:ADP ratio. This increase inactivates the $\mathrm{K}^{+}$channel that depolarises the membrane, causing the $\mathrm{Ca}^{2+}$ channel to open up and allowing Ca ${ }^{2+}$ ions to flow inward. The ensuing increase in levels of $\mathrm{Ca}^{2+}$ ions leads to the exocytotic release of pre-synthesised insulin stored in vesicles. Finally, insulin is released from the storage vesicles.

(CREB). This mechanism of glucose action on insulin secretion is similar to that in the pancreas and the brain [55].

\section{GLUCOSE AND ITS TRANSPORT IN THE BRAIN}

Glucose is an essential fuel for the body and its metabolism is crucial for the brain. Glucose is metabolised by glycolysis and oxidative breakdown in both astrocytes and neurons. Neurovascular and neurometabolic coupling help the brain to maintain an appropriate energy flow to neural tissues under conditions of increased neuronal activity. Glucose in the CNS is transported via facilitated diffusion. This is mediated by a certain glucose transporter family termed "GLUT". These transporters are localised to the BBB, endothelial cells and cortical membranes. In the brain, GLUT1, GLUT2 and GLUT5 are expressed predominantly in a cell-specific manner [56-58]. Two forms of GLUT1 exist in the brain at different molecular weights (MW): $55 \mathrm{kDa}$ and $45 \mathrm{kDa}$. The MW depends on the degree of glycosylation of GLUT1. The $55 \mathrm{kDa}$ form is essentially localised to brain microvessels, choroid plexus and vascular endothelial cells, whereas the $45 \mathrm{kDa}$ form is found predominantly in astrocytes [59, 60]. Although GLUT3 is considered specific to neurons, it has also been detected in brain astroglial cells, brain endothelial cells and other tissues such as the placenta, liver and kidney. GLUT5 is localised to microglial cells, the resident macrophages of the brain. It plays a pivotal role in the immune and inflammatory responses of the nervous system and can also be found in the brain endothelium. Another member of the GLUT family,
GLUT2, is selectively localised to astrocytes of discrete brain areas such as the hypothalamic and brain stem nuclei. These areas participate in the regulation of feeding behaviour and in the central control of insulin release. Other GLUT members that are selectively dispersed in the brain are the insulin-sensitive GLUT4 and GLUT8. GLUT4 is also found in the pituitary and the hypothalamus. However, GLUT8 is expressed only in the hippocampus, the cerebral cortex and the hypothalamus [61-63]. In actuality, glucose enters the brain through the $55 \mathrm{kDa}$ GLUT1 transporters of the endothelial cells of the BBB. In astrocytes, glucose uptake is mediated by the $45 \mathrm{kDa}$ GLUT1 transporters, whereas GLUT3 transporters mediate this process in neurons. Finally, GLUT5 has been found to mediate the uptake of an unidentified substrate into microglial cells [64].

\section{INSULIN AND ITS RECEPTORS IN THE BRAIN}

The most contentious feature of brain insulin research concerns the origin of insulin in the brain. Insulin in the brain basically originates from pancreatic $\beta$-cells, but is also partially formed in pyramidal neurons such as those in the hippocampus, the prefrontal cortex, the entorhinal cortex and the olfactory bulb; however, it is not synthesized by glial cells. Insulin can enter circum ventricular regions that lack a $\mathrm{BBB}$, and it can also cross the BBB via insulin transportermediated active transport [65]. Insulin gene expression and synthesis have been demonstrated in both mature and immature mammalian neuronal cells, yet the consensus is that little or no insulin is produced in the CNS [66]. Insulin 
acts as a mediator in the communication between the peripheral endocrine system and the brain via various steps of the neuroendocrine axis. The insulin receptor is a heterotetrameric tyrosine kinase receptor that undergoes dimerisation and tyrosine autophosphorylation upon binding insulin. Insulin receptors are widely distributed in the brain, with the highest densities in the olfactory bulb, the hypothalamus, the cerebral cortex and the hippocampus [67]. In the brain, insulin/insulin-like growth factor 1 (IGF1) and their cognate receptors regulate a multitude of processes such as glucose metabolism, neuronal differentiation, stem cell proliferation, cellular repair mechanisms and cognitive function [68, 69]. Increased concentration of peripheral insulin modulates $\mathrm{BBB}$ insulin transporters to regulate its transport into the brain [66, 70]. IGF1 is also synthesised locally in many tissues, including the brain. In contrast to insulin, IGF1 in the circulation and in tissues is bound to high affinity IGF binding proteins (IGFBPs) [71]. The receptor for IGF1 is structurally similar to the insulin receptor; both are tyrosine kinases that phosphorylate similar insulin receptor substrate proteins [72]. Glucose metabolism and insulin receptor mediated signal transduction control the activity of several enzymes involved in the generation of the APP derivative $A \beta$ and the phosphorylation of the Tau protein, the two hallmarks of AD.

\section{INSULIN/IGF1 SIGNALLING PATHWAYS AND AD}

\section{Insulin/IGF1 Signalling in APP Processing}

Impaired insulin and insulin-like growth factor expression and signaling mechanisms are found in $\mathrm{AD}$ and considered as type 3 diabetes [70, 73, 74]. Insulin and IGF1 receptors are tyrosine kinases that mediate the phosphorylation of insulin receptor substrates (IRSs) including IRS1-4. Phosphorylated IRS proteins activate multiple signalling pathways that include PI3K and the extracellular signal-regulated kinase (ERK) cascades, which directly modulate various physiological processes [75]. PI3K is an important mediator of the metabolic signalling pathway. This kinase is a dimer composed of a $110-\mathrm{kDa}$ catalytic subunit and a $\mathrm{p} 55-\mathrm{kDa}$ or $\mathrm{p} 85-\mathrm{kDa}$ regulatory subunit. Tyrosine-phosphorylated IRS associates with the two $\mathrm{SH} 2$ domains of the regulatory subunit $\mathrm{p} 85$, which in turn binds the catalytic subunit p110. PI3K is insulin regulated and activates protein kinase $\mathrm{B}(\mathrm{PKB})$, otherwise known as AKT. Activated PI3K also promotes the growth of cortical pyramidal neurons that play a key role in learning and memory $[76,77]$. AKT then regulates the activity of the glycogen synthase kinase- $3 \alpha / \beta \quad($ GSK-3 $\alpha / \beta)$. GSK-3 $\beta$ contributes to the hyper-phosphorylation of Tau [78] and regulates the production of the APP derivative $A \beta$, which is generated intracellularly in the ER/Golgi apparatus [79]. GSK-3 $\beta$ is also functionally important for regulating glycogen metabolism, cell cycle kinetics, proliferation, survival and cell migration. AKT inhibits GSK-3 $\beta$, which promotes cellular metabolism, proliferation and cell survival (Fig. 3). Simultaneous release of GSK-3 $\alpha$ may promote the storage and misfolding of APP metabolites. The subsequent accumulation of $\mathrm{A} \beta 42$ leads to neurite and neuronal degeneration [79].

Transcription of the genes for insulin and IGF1 receptors is reduced in $\mathrm{AD}$ brains compared with controls [80, 81]. AD brains also demonstrate reduced expression of the IRS, IRS-

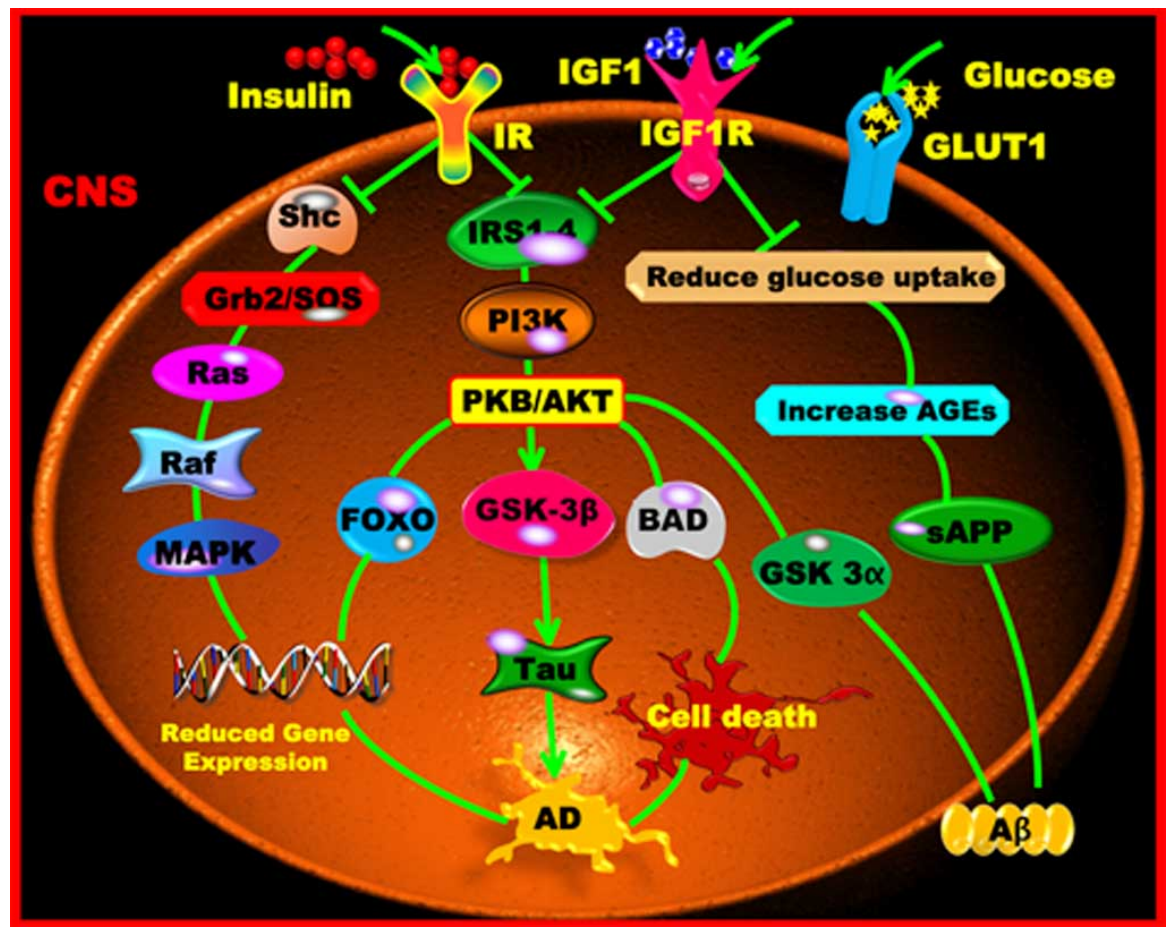

Fig. (3). Insulin/IGF1 signalling pathways and AD. Insulin or IGF1 binds with its respective specific receptor sites to activate the IRS proteins that enter the PI3K and PKB/AKT pathways. These pathways cross the GSK-3 $\beta$ and thereby produce the Tau hyper-phosphorylation characteristic for AD. The alternative pathway leads to Shc, Grb2/SOS, Ras, Raf, MAPK activation and gene expression. The absence of IGF1 leads to decreased glucose uptake, decreased glycogen and protein synthesis, an increased level of AGEs, increased Tau phosphorylation and thus increased apoptosis. 
associated PI3K, and activated AKT/PKB [82], suggesting downstream abnormalities in insulin/IGF intracellular signalling mechanisms. As mentioned earlier, activation or inhibition of these signalling mechanisms can influence the metabolism of APP and A $\beta$. IGF1 also blocks $A \beta$ toxicity in primary cultures of hippocampal neurons. This inhibition of $A \beta$ toxicity occurs through the activation of ERK and $\mathrm{AKT} / \mathrm{PKB}$ and the prevention of c-Jun N-terminal kinase (JNK) activation in a PI3K-dependent manner [74, 83]. Recent studies provide further support for PI3K as a modulator of APP trafficking and demonstrate that overactivation of the insulin/IGF-1 signaling pathway may result in feedback inhibition of PI3K through IRS1 and reduced APP trafficking and $A \beta$ secretion [84]. In vivo, insulin/IGF1 signalling is strongly neuroprotective in a variety of AD models. For example, IGF1 protects against mutant APP signalling and chronic subcutaneous infusion of IGF1 has been reported to reduce $\mathrm{CNS} A \beta$ levels in aging rats and amyloid plaques in the $\mathrm{AD}$ transgenic mouse ( $\mathrm{Tg} 2576$ ) model [85-87]. Indeed, IGF1R may activate a common signaling cascade that now seems to link aging to ageassociated pathologies of the brain [88]. A disturbed cross talk between IGF1 and AMP-activated protein kinase might be a possible cause that could underlie vascular dysfunctions observed in AD [89].

\section{Insulin/IGF1 Signalling in Tau Phosphorylation}

Impaired insulin/IGF1 signalling results in the hyperphosphorylation of Tau due to reduced activation of PI3K/AKT and increased levels of GSK-3 $\beta$ activity (Fig. 3). Tau is normally phosphorylated by GSK-3 $\beta$ and dephosphorylated by the protein phosphatase PP2A [90, 91]. In addition, GSK-3 $\beta$ can be activated through the inhibition of insulin/IGF1 signalling via the Wnt pathway, which is not dependent on PI3K/AKT phosphorylation. Impairment of Wnt signalling mechanisms have been proposed as one key molecular abnormalities in AD [92]. Hyper-phosphorylated Tau fails to be transported into axons and instead accumulates and aggregates in neuronal perikarya, where it promotes oxidative stress that can cause cell death mediated by apoptosis, mitochondrial dysfunction or necrosis. Therefore, the decreased phosphorylation of GSK-3 $\beta$ observed in NIRKO mice results in an increase in GSK-3 $\beta$ activity and may cause elevated Tau phosphorylation [93]. Another study used a mouse model in which the disruption of IR tyrosine kinase signalling led to an accumulation of phosphorylated Tau in the hippocampus. ERK, mitogenactivated protein kinase (MAPK) and cyclin-dependent kinase 5 (CDK-5) are important for the physiological phosphorylation of Tau protein, both of which are activated by insulin/IGF1 receptor. A deficit in insulin concentration increases the activity of GSK-3 $\beta$, which has been found to cause Tau hyper-phosphorylation and APP metabolism. This may suppress neuronal survival under neurodegenerative conditions [94-96].

\section{DIABETIC COMPLICATIONS AND NEURODEGEN- ERATION}

Insulin resistance and hyperinsulinaemia are associated with elevated inflammatory markers and increase the risk of AD [97]. The hallmarks of insulin resistance include selective impairment of the PI3K intracellular signalling pathway in response to insulin, compensatory hyperinsulinaemia, elevated free fatty acids (FFA) and inflammation. PKC and DAG signalling pathways are affected during insulin resistance as well. PKC and DAG are intracellular signalling molecules that regulate vasculature through endothelial permeability and vasodilation. The PKC isozymes are a family of 12 related serine/threonine kinases whose normal function is to activate proteins and lipids that are essential for cell survival. PKC activation is a critical step in the pathway to diabetic microvascular complications [98]. This activation leads to changes in vascular permeability, the extracellular matrix (ECM) synthesis, cytokine synthesis, smooth muscle contraction and angiogenesis, as well as oxidative and osmolar stress, both of which are a consequence of the dysmetabolism of diabetes. Increased DAG and $\mathrm{Ca}^{2+}$ promote the overactivation of PKC- $\beta$.

PKC- $\beta$ over-activation is induced by hyperglycaemia or fatty acids through receptor-mediated activation by PLC. Increased PKC activity and disordered FFA metabolism have been implicated in the over-expression of the angiogenic vascular endothelial growth factor (VEGF), nuclear factor-kappa $\mathrm{B}(\mathrm{NF}-\kappa \mathrm{B})$, transforming growth factor$\beta$ (TGF- $\beta$ ), endothelin-1 (ET-1), and intercellular adhesion molecules (ICAMs). It is also involved in the development of diabetic complications such as retinopathy, nephropathy and $\mathrm{CD}$ [99]. PKC- $\beta$ hyperactivity leads to increased vascular permeability, NO dysregulation, and increased leukocyte adhesion, and it is believed to be involved in cell proliferation, differentiation and apoptosis. Furthermore, PKC- $\beta$ hyperactivity in neural microvessels causes vasoconstriction. This may lead to decreased blood flow, resulting in hypoxia followed by nerve dysfunction in the brain. Additionally, PKC- $\beta$ activates MAPK, which subsequently phosphorylates transcription factors that are involved in angiogenesis as well as expression of stressrelated genes, JNK and heat shock proteins [100]. VEGF plays a critical role not only in angiogenesis but also in the development of the nervous system [101]. Diabetic animal models have shown high levels of PKC- $\beta$ in a number of tissues including nerves and endothelium. This may further accelerate the loss of nerve conduction [102].

Elevated blood glucose may be directly toxic to nerves and intravenous infusions of glucose increase neuropathic pain [103]. Hyperglycaemia causes the activation of the polyol pathway, leading to the conversion of glucose into sorbitol by aldose reductase (Fig. 4). The accumulation of the organic osmolyte sorbitol leads to compensatory depletion of other intercellular osmolytes, such as myoinositol and taurine, which in turn leads to reduced $\mathrm{Na}^{+} / \mathrm{K}^{+}$adenosine triphosphatase (ATPase) activity. The polyol pathway also generates fructose, which together with several other compounds such as glucose, glucose-6phosphate and galactose stimulates the non-enzymatic glycation reaction. This is another metabolic effect of hyperglycaemia. In this process, reduction of sugars forms reversible glycosylation products with proteins, some of which rearrange to form irreversible AGEs [104]. These AGEs can crosslink proteins, including neurofilaments and basement membrane components. Vascular abnormalities observed in patients with diabetic polyneuropathy include basement membrane thickening, endothelial hyperplasia, 


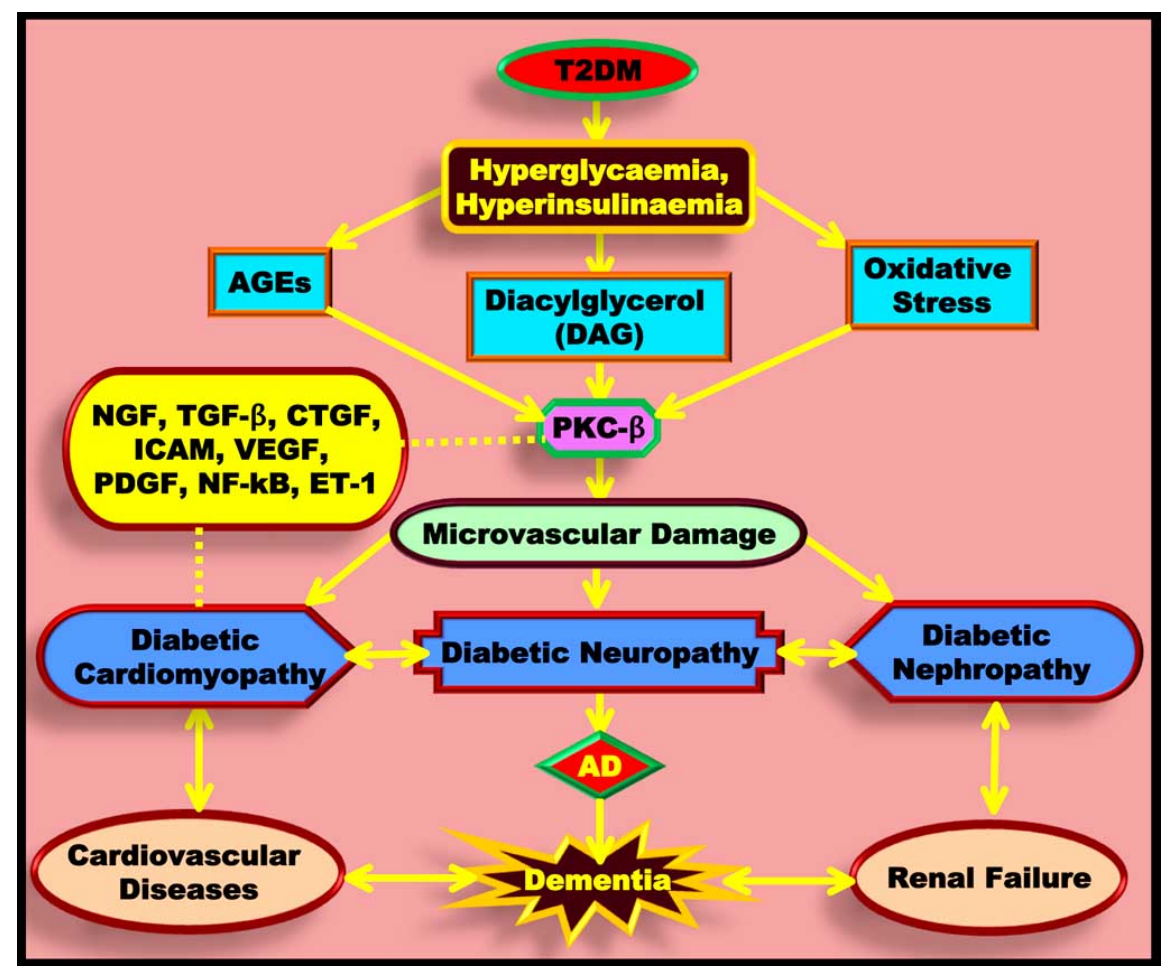

Fig. (4). Diabetic complications and neurodegeneration. In diabetes, hyperglycaemia leads to the formation of DAG, AGEs and oxidative stress. These factors enter the PKC- $\beta$ pathway and produce microvascular damage characteristic of diabetic cardiomyopathy, diabetic neuropathy and diabetic nephropathy.

endothelial dysfunction, increased expression of endothelin and alterations in VEGF expression. Pathologic studies of proximal and distal segments of nerves in diabetic polyneuropathy have shown multifocal fibre loss along the length of the nerves, suggesting ischaemia as a pathogenetic contributor [105]. Vascular and metabolic mechanisms likely interact; hyperglycaemia has a number of deleterious effects on blood vessels [106]. Vessel wall matrix proteins may be affected by non-enzymatic glycation. Hyperglycaemia can lead to increased oxidative stress with the production of superoxides and NO. These substances can interact, leading to protein nitration or nitrosylation, lipid peroxidation, DNA damage and endothelial and neuronal cell death. Superoxides also lead to the activation of PKC, which induces vasoconstriction and reduces neuronal blood flow [107].

Diabetic retinopathy (DR) is the most specific microvascular complication and one of the leading causes of visual impairment in diabetic patients. DR complications result from functional and morphological alterations of retinal capillaries, increased permeability to albumin and macromolecules, vascular dysfunction, loss of pericytes and basement membrane thickening. The classic risk factors for diabetic retinopathy are hyperglycaemia, hypertension and hyperlipidaemia. These cardiovascular risk factors are important for both the initial development of diabetic retinopathy and the subsequent progression to advanced retinopathy [108].

Diabetic nephropathy (DN) is a chronic kidney disease characterised by abnormal deposits of matrix material in the glomerular mesangium, leading to glomerulosclerosis. This disorder is also known as intercapillary glomerulonephritis and is described histopathologically by axonal degeneration, demyelination and atrophy, in association with failed axonal regeneration, remyelination and synaptogenesis [109, 110]. DN typically affects the network of tiny blood vessels in the glomerulus, which is necessary for the filtration of blood. The pathophysiology of DN suggests that complex interactions exist between multiple pathways. These include abnormalities in glucose transport mechanisms, increased activity of specific intracellular metabolic pathways, activation of $\mathrm{PKC}$ isoforms, formation of reactive oxygen species (ROS) and increased production of AGEs. Altered activity of a variety of growth factors and cytokines may be critical factors in the development of microvascular diabetic complications including nephropathy $[111,112]$.

\section{ENDOTHELIAL DYSFUNCTION IS A BRIDGE BETWEEN T2DM AND CARDIOVASCULAR DIS- EASES}

The endothelium is a single layer of cells that lines all vessels in the body, including conduit vessels, resistance vessels, pre-capillary arterioles and capillaries. By virtue of its direct contact with the circulating blood, the endothelial layer provides a critical interface between the elements of blood and the tissues. The function of each vessel and the role of its respective endothelium vary according to its location in the body. In the conduit vessels, which include larger arteries such as the aorta and the carotid/coronary/ brachial/femoral arteries, a healthy endothelium provides a smooth, quiescent surface that limits the activation of clotting and proinflammatory factors. This endothelium also blocks the transfer of lipid particles into the arterial wall, inhibits the release of chemokines/cytokines/growth factors 
and prevents adhesion of platelets and monocytes to the vascular endothelium. In the resistance vessels, endothelial cells (ECs) help to regulate blood flow and systemic blood pressure, whereas in the precapillary arterioles, they play a role in the transport and disposal of waste products of metabolism as well as the distribution of nutrients and hormones such as glucose, fat and insulin. ECs protect blood vessels not only by providing a mechanical lining, but also by controlling vascular tone, inflammation, and thrombosis [113]. EC production of NO and prostacyclin causes vasodilatation, whereas ET-1 mediates vasoconstriction [114]. Inflammatory molecules produced by ECs include interleukin-1 (IL-1), IL-6, IL-18, tumour necrosis factor- $\alpha$ (TNF- $\alpha$ ), monocyte chemoattractant protein-1 (MCP-1) and a number of adhesion molecules. Compelling evidence supports endothelial dysfunction as a key early event in the pathogenesis of atherosclerosis. The term endothelial dysfunction encompasses several potential abnormalities; the most extensively studied anomalous characteristic is a reduction in the bioavailability of NO. NO is an antiatherosclerotic signalling molecule released by the vascular endothelium that has potent vasodilatory, antiinflammatory, anti-proliferative, anti-oxidant, and antiplatelet effects. NO bioavailability is reduced in atherosclerotic vessels before vascular structural changes occur. Impaired NO-dependent vasodilatation is a predictor of future cardiac events and the development of coronary artery atherosclerosis [115-117].

In ECs, insulin increases peripheral vascular blood flow by simulating NO production. FFAs inhibit the insulininduced increase in peripheral venous $\mathrm{NO}$ and peripheral blood flow via two pathways. As illustrated (Fig. 5), the first pathway involves reduction of the tyrosine phosphorylation of IRS-1/2. FFAs inhibit the PI3K/AKT pathway, which, aside from controlling insulin-stimulated glucose uptake, is also needed to stimulate endothelial NOS (e-NOS). Thus, the production of NO in ECs is inhibited. The second inhibitory pathway involves FFA activation of NADPH oxidase in a DAG/PKC-dependent manner. Activation of NADPH oxidase leads to the production of ROS, which results in the destruction of NO [118, 119]. The lipid metabolites activate serine kinases such as PKC and inhibitory $\kappa \mathrm{B}$ kinase (IкB), which regulate the activation of nuclear factor $-\kappa B(N F-\kappa B)$, a transcription factor associated with inflammation. The aberrant regulation of $\mathrm{NF}-\kappa \mathrm{B}$ is associated with a number of chronic diseases including diabetes and atherosclerosis [120]. NF- $\kappa \mathrm{B}$ is activated through a common pathway that involves the phosphorylation-induced, proteasome-mediated degradation of the inhibitory subunit $I \kappa B$. $I \kappa B$ is phosphorylated by the upstream serine kinase IKK, which is phosphorylated and activated by additional upstream serine kinases. Elevated plasma FFA levels also produce low-grade inflammation in skeletal muscle and liver via activation of the NF- $\kappa \mathrm{B}$ pathway. This results in the synthesis and release of pro-inflammatory and pro-atherogenic cytokines. Likewise, palmitate activates IKK and JNK, thereby increasing serine phosphorylation of IRS and decreasing insulin stimulated production of NO. In healthy people, insulin infusion results in the release of both NO and ET-1 in adequate concentrations to ensure an appropriate balance for maintaining vascular tone. In contrast, in diabetic patients there is an increased production of ET-1 that creates a vasoconstrictive environment to further impair endothelial function [121]. At the molecular level, insulin exerts its effects through the PI3K or MAPK pathways. In insulin resistance states, the activation of the PI3K pathway is inhibited, whereas the activation of the MAPK pathway is largely intact. The net result is a reduction in vasodilatation and an increase in vasoconstriction, inflammation, and thrombosis that explains much of the increased atherothrombotic risk in diabetic patients [122]. The accumulation of AGE products in diabetes impairs EC function in animal models. Furthermore, AGE products promote vascular inflammation and induce ROS accumulation, and both of these processes contribute to endothelial dysfunction via inhibition of NO production. In addition, acute hyperglycaemia can result in NO reduction and attenuation of endothelium-dependent vasodilatation. Therefore, vascular endothelial dysfunction may occur at any or all levels in the arterial system and contributes to the development and progression of atherosclerosis by favouring coagulation, cell adhesion, and inflammation. This is achieved by promotion of inappropriate vasoconstriction or vasodilation and by enhancement of transendothelial transport of atherogenic lipoproteins [123].

\section{ROLE OF CYTOKINES IN NEUROINFLAMMATION AND AD}

Cytokines also play critical roles in the development and progression of AD. Cells associated with extracellular plaques within the brains of $\mathrm{AD}$ patients can produce a variety of cytokines and other related proteins that can ultimately influence plaque and tangle formation. Additionally, $A \beta$ itself can stimulate microglia and astrocytes to secrete pro-inflammatory cytokines, chemokines and reactive ROS, which can lead to neuronal damage [16]. The overproduced cytokines generate a "vicious circle" leading to irreversible synaptic loss and consequently to behaviour alterations. Five major cytokines have been extensively studied in relation to $\mathrm{AD}$ onset or progression. Four are pro-inflammatory cytokines: IL- $1 \alpha$, IL$1 \beta$, TNF- $\alpha$ and IL-6. TGF- $\beta$ mainly has an anti-inflammatory role [124]. TNF- $\alpha$ is a critical component of the brain's immune system. Normally, TNF finely regulates the transmission of neural impulses in the brain. Excess TNF- $\alpha$ has been documented in the cerebrospinal fluid of patients with AD [125]. In addition to being secreted by astroglia and microglia, circulating peripheral TNF- $\alpha$ can diffuse through the BBB and access brain cells.

During neuropathologic and neurodegenerative conditions, the level of brain TNF- $\alpha$ increases dramatically, suggesting a significant role of this cytokine in these processes. Whereas the pro-inflammatory effects of TNF- $\alpha$ are most relevant at later stages, TNF- $\alpha$ also has neuroprotective and regenerative functions during the early processes of neurodegenerative diseases [126]. TNF- $\alpha$ has both neurotoxic and neuroprotective effects mediated, respectively, by two receptor subtypes: TNF receptors 1 and 2 (TNFR1 and TNFR2). These two receptors trigger the activation of NF- $\kappa \mathrm{B}$. Most neuroprotective roles of TNF- $\alpha$ are mediated via conscription of $\mathrm{NF}-\kappa \mathrm{B}$. In addition to direct IKK mediated activation, NF- $\kappa \mathrm{B}$ can also be activated via pro survival kinases such as AKT/PKB. Activated NF- $\kappa B$ dimers enter the nucleus and influence the expression of a 


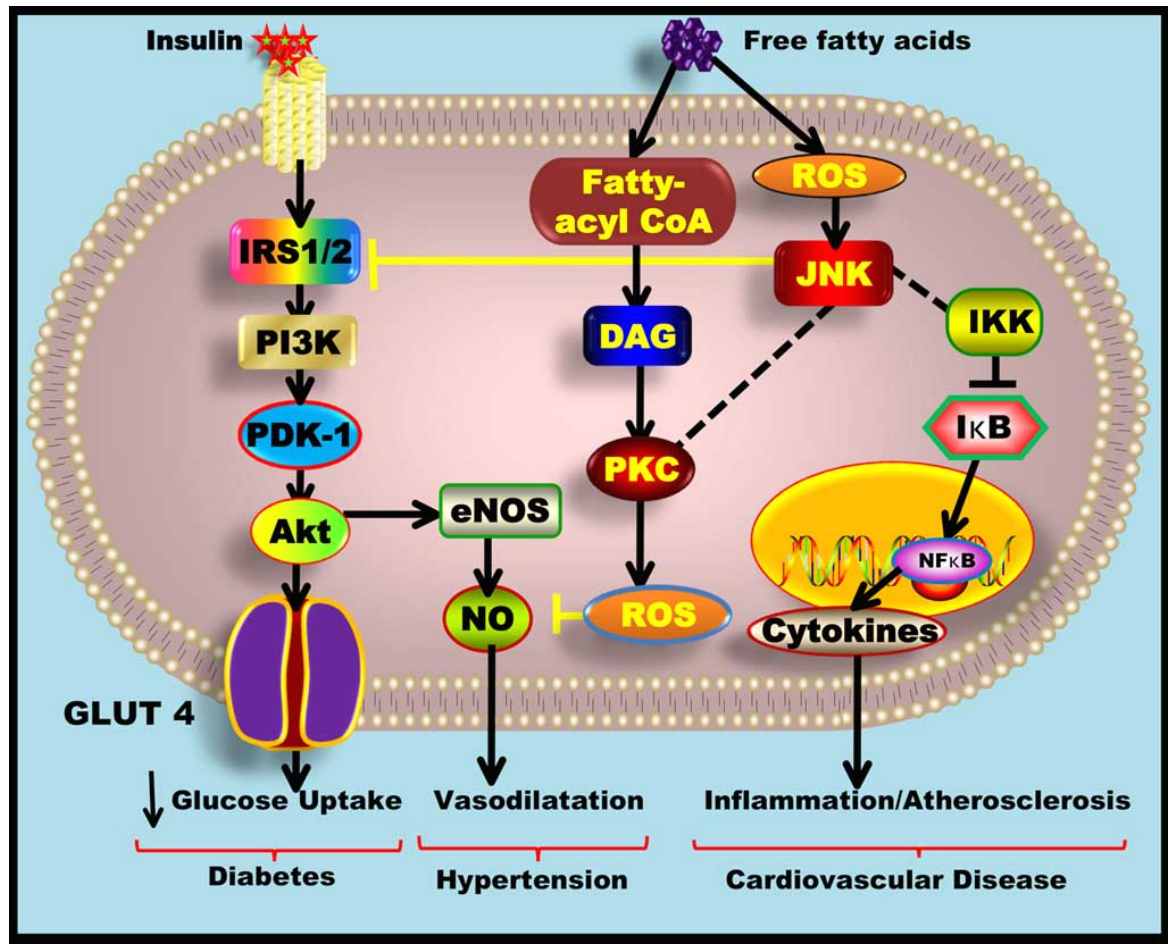

Fig. (5). Endothelial dysfunction is a bridge between T2DM and cardiovascular diseases. Increased levels of FFA and DAG trigger a serine/threonine kinase cascade, ultimately inducing serine/threonine phosphorylation of critical IRS-1 sites and thereby inhibiting IRS-1 binding and the activation of PI3-kinase, which results in reduced insulin-stimulated glucose transport.

complex array of genes constituting the neuronal response to various neurodegenerative disorders. In particular, neuronal $\mathrm{NF}-\kappa \mathrm{B}$ is proposed to be neuroprotective in nature [127]. In contrast, neurotoxic TNF- $\alpha$ inhibits the transport of $A \beta$ from the brain to the periphery, and elevated TNF- $\alpha$ levels may increase brain accumulation of $\mathrm{A} \beta$ [86]. Paradoxically, TNFR1 contains a death receptor domain and has been implicated in pro-apoptotic events, whereas TNFR2 promotes cell survival [128]. Increased levels of TNFR1 and decreased levels of TNFR2 have been observed in AD brains and in peripheral lymphocytes from older adults compared with younger adults though others say that the receptors may not play a major role in the development of AD [129-131]. A 342 interacts with inflammatory agents in a cyclically reinforcing manner, such that $A \beta$ elevations increase levels of pro-inflammatory cytokines [132]. In vitro, soluble $\mathrm{A} \beta$ oligomers rapidly increase the levels of IL-1 $\beta$ and TNF- $\alpha$. Conversely, IL- 6 and IL- $1 \beta$ can regulate the processing of APP, from which A $\beta$ is derived, and increase the production of $\mathrm{A} \beta 42$ [133].

\section{ROLE OF ADVANCED GLYCATION END PRO- DUCTS (AGES) IN DIABETIC VASCULAR DISEASES AND AD}

Glucose and other reducing sugars react nonenzymatically with protein amino groups to initiate a posttranslational modification process known as non-enzymatic glycosylation. This reaction proceeds from reversible Schiff bases to stable, covalently bonded Amadori rearrangement products. Once formed, the Amadori products undergo further chemical rearrangement reactions to form irreversibly bound AGEs, which play a significant role in the pathogenesis of the chronic complications of diabetes mellitus (Fig. 6) [134]. AGEs are a heterogeneous group of structures; those that have already been identified include pyrraline, pentosidine, crossline, and carboxymethyl lysine (CML). These biomolecules are found both inside and outside of cells. Intracellularly, AGEs generally alter functions and cellular transport. However, AGEs that are present extracellularly disrupt cellular adhesion and activate the AGE receptor (RAGE). AGE is used for a broad range of glycation processes (also called the "Maillard reaction"). Hence, hyperglycaemia leads to the formation of AGEs in high concentrations. AGEs have been implicated in the development of oxidative stress, as well as in T2DM. They also play a role in atherosclerosis and renal insufficiency during aging [135]. RAGE is a member of the immunoglobulin superfamily of cell surface molecules and is expressed in a variety of cell types, including ECs, pericytes, mesangial cells, neurons and glia. The receptor-mediated reactions may further contribute to neuronal degeneration. AGE formation causes increased stiffness in the cardiovascular system, leading to high blood pressure and modification of functionally important proteins like tubulin and ATPases. The formation of AGEs is also associated with the increased production of ROS. ROS is also linked to the pathophysiological model of non-enzymatic glycation effects on oxidative stress. The binding of RAGE by AGEs is capable of mediating inflammatory responses and oxidative stress and leads to diabetic vascular complications [136, 137]. AGEs cause many effects, such as blockage of transport through cell membranes, blockage of protein synthesis, reduction of tissue strength and elasticity and fragmentation of molecules that include DNA [138]. AGE 


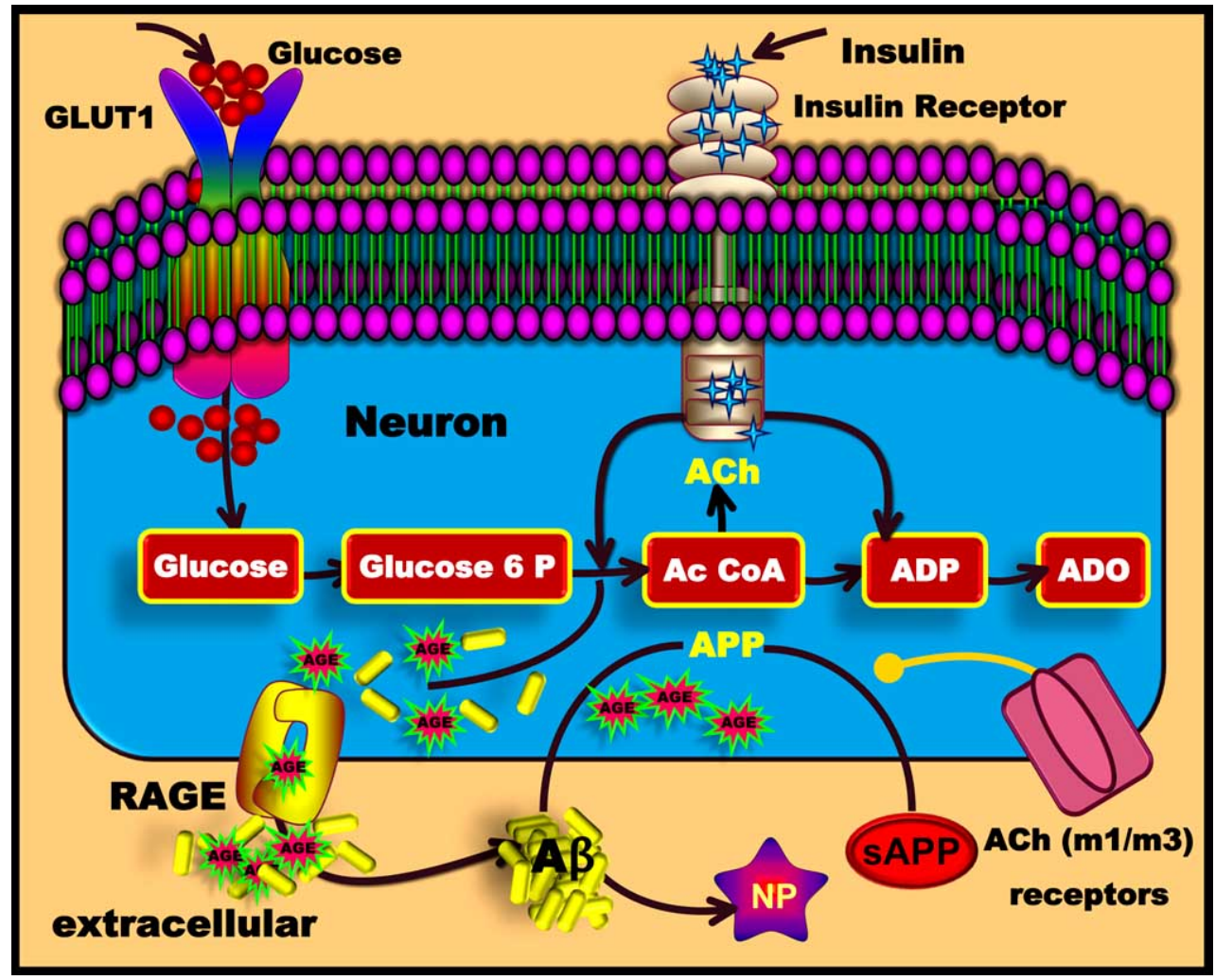

Fig. (6). Formation of advanced glycation end products (AGEs) in diabetic vascular diseases and AD. Glucose enters the cell and the glycolytic and tricarboxylic acid (TCA) pathways and eventually produces ATP and amino acids. AGEs are formed from reactions between carbohydrates and proteins. Subsequently, AGEs bind to the RAGE receptors. The RAGE receptor helps A $\beta$ to cross the BBB, after which $\mathrm{A} \beta$ forms neuritic plaques (NP).

immunoreactivity is associated with pathologic hallmarks of AD (NFTs and NPs), cortical neurons, microglia, astrocytes and blood vessels in AD brains [139, 140]. The most prominent species of AGEs in tissues, N-epsilon-CML adducts, are found at their highest levels in the hippocampus. Levels of CML expression in neurons are correlated with NFT pathology. Interestingly, AD patients with T2DM showed enhanced formation of CML, possibly owing to the increased levels of glucose and enhanced oxidative stress [136]. Astrocytes were the major brain cell type shown to contain AGE products by immunohistochemical techniques that involved antibody reaction with AGEs [141]. AGEimmunoreactive astrocytes are also associated with mature amyloid plaques and express elevated neuronal NOS (nNOS). In cultured astrocytes, AGEs increase the release of IL-1 $\beta$, TNF- $\alpha$ and NO. In a murine microglial cell line, RAGE was shown to be involved in AGE-mediated generation of IL-6, TNF- $\alpha$ and NO. AGEs, in combination with endogenous NO, increased ROS production, resulting in caspase-3-dependent apoptosis in SH-SY5Y neuroblastoma cells [142].

During normal aging, AGEs accumulate in the brain; this accumulation is implicated in the pathogenesis of AD. AGE products bind to RAGE, which is present in neurons and binds to amyloidogenic APP derivative A $\beta$ [143]. A $\beta$ interaction with RAGE on ECs leads to the transport of $A \beta$ across the $\mathrm{BBB}$ and the expression of pro-inflammatory cytokines in those cells [144]. It has also been shown that RAGE stimulates functional BACE1 expression through nuclear factor of activated T-cells 1 (NFAT1) activation, resulting in more $A \beta$ production and deposition in the brain [145]. The deposition of $\mathrm{A} \beta$ peptides is thought to be an early and causative event in the pathogenesis of $\mathrm{AD}$ and increases markedly during the progression of the disease, leading in turn to the generation of NFTs and finally neuronal death $[136,146]$.

\section{CHOLESTEROL SYNTHESIS, TRANSPORT AND METABOLISM IN THE BRAIN}

Cholesterol is a necessary component of all cell membranes and is important both as a structural component and as a modulator of cell membrane fluidity. Cholesterol is a waxy, fat-like compound that belongs to a class of molecules called steroids. It maintains the integrity of cell membranes and functions to resist changes in temperature and to protect and insulate nerve fibres. It is also involved in the formation of sex hormones (progesterone, testosterone, estradiol, cortisol) and the production of bile salts, which help to digest food. Furthermore, it is converted into vitamin $\mathrm{D}$ in the skin when exposed to sunlight. Cholesterol is synthesised in the liver and the brain and can also be obtained through a diet of animal products [147]. It is highly enriched in the brain in comparison with other tissues. In the blood, it is carried on lipoproteins that are classified into chylomicrons, very low-density lipoproteins (VLDL), intermediate-density lipoproteins (IDL), low-density lipoproteins (LDL) and high-density lipoproteins (HDL) [148]. 


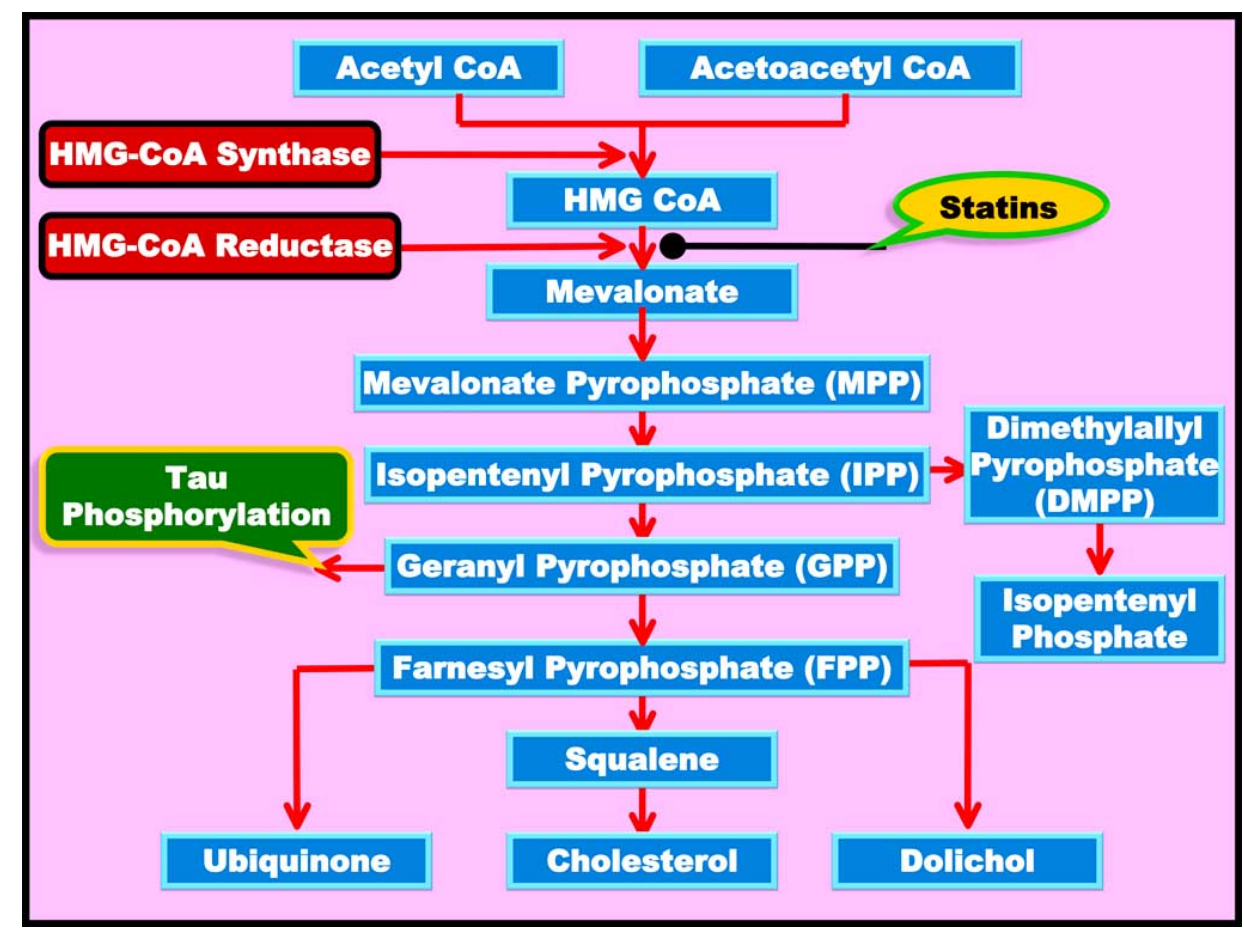

Fig. (7). Cholesterol synthesis in the brain. Acetyl CoA and acetoacetyl CoA combine to form HMG CoA. The conversion of HMG CoA to mevalonate by HMG CoA reductase is the main regulatory step in the overall pathway. Statins are inhibitors of HMG CoA reductase and inhibit the cholesterol biosynthesis pathway.

The majority of cholesterol present in the brain is synthesised in the CNS. The brain is the most cholesterolrich organ in the body and contains about $25 \%$ of the total body cholesterol. Cholesterol synthesis begins with the transport of acetyl-CoA from the mitochondria to the cytosol [149]. For every reversal of the thiolase reaction, two molecules of acetyl-CoA are condensed to form acetoacetylCoA. Acetoacetyl-CoA and a third molecule of acetyl-CoA are converted to HMG-CoA with the aid of HMG-CoA synthase (Fig. 7). HMG-CoA is converted to mevalonate by HMG-CoA reductase. Mevalonate is then activated by three successive phosphorylations, yielding mevalonate pyrophosphate (MPP). In addition to activating mevalonate, these phosphorylations maintain solubility. After phosphorylation, ATP-dependent decarboxylation yields isopentenyl pyrophosphate (IPP), an activated isoprenoid molecule. IPP is in equilibrium with its isomer, dimethylallyl pyrophosphate (DMPP). One molecule of IPP is condensed with one molecule of DMPP to generate geranyl pyrophosphate (GPP). GPP is further condensed with another IPP molecule to yield farnesyl pyrophosphate (FPP). Thereafter, the NADPH-requiring enzyme squalene synthase catalyses the head-to-tail condensation of two molecules of FPP, yielding squalene (squalene synthase is also tightly associated with the ER). Squalene then undergoes a two step cyclisation to yield inosterol. Finally, the inosterol is converted into cholesterol [147].

Transport of cholesterol from the peripheral circulation into the brain is prevented by an intact BBB. In the CNS, essentially all cholesterol is unesterified and the majority of cholesterol is localised in the myelin sheaths formed by oligodendrocytes. The remaining brain cholesterol is found in neurons, glial cells and extracellular proteins. These pools of cholesterol participate in cholesterol homeostasis of the CNS $[150,151]$. Both dietary cholesterol and cholesterol that are synthesised de novo are transported through the circulation in lipoprotein particles [152]. The same is true of cholesterol esters (CEs), the form in which cholesterol is stored in cells. The synthesis and utilisation of cholesterol must be tightly regulated in order to prevent overaccumulation and abnormal deposition within the body. Cholesterol plays an important part in the regulation of $\mathrm{A} \beta$ production, with high cholesterol levels being linked to increased $A \beta$ generation and deposition [153]. Abnormalities in the cholesterol metabolism contribute to the development of atherosclerosis, heart disease and $\mathrm{AD}[154,155]$.

Cholesterol is insoluble in the blood and therefore needs carriers known as lipoproteins to aid in its transportation to cells. Astrocytes not only synthesise but also internalise and recycle cholesterol that has been released from degenerating nerve terminals. Astrocytes have the highest capacity to produce ApoE. ApoE binds cholesterol and acts as a ligand for cell surface-lipoprotein receptors such as LDL-receptorrelated proteins (LRP), illustrated in (Fig. 8). ApoE is one of the major apolipoproteins found in the plasma. There are spherical and discoidal shaped HDL particles. Under normal conditions, this is an important protein for cholesterol function in the brain and within the CNS; it has the important metabolic function of regulating lipid transport into neurons and clearing cholesterol from ECM [156]. Neurons and glial cells contain LRP receptors, which are large endocytic membrane receptors that can bind and internalise the ApoE-cholesterol phospholipid complex and then fuse with lysosomes. Lysosomes are vesicles that contain the necessary hydrolytic enzymes to allow the intracellular release of free cholesterol (FC). The ATP- 


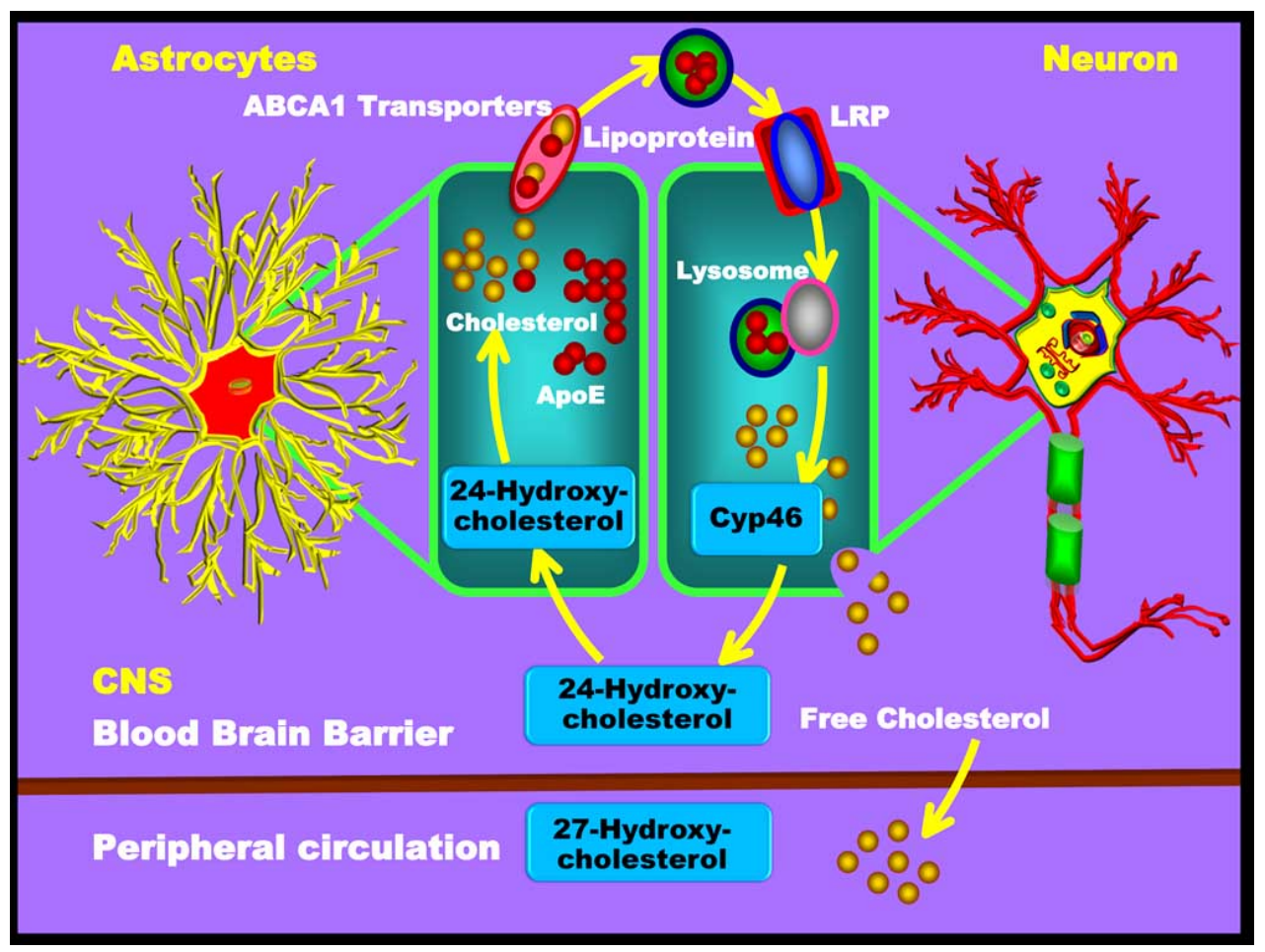

Fig. (8). Cholesterol transport and metabolism in the brain. Cholesterol is mainly generated in astrocytes and is then transported to neurons. Cholesterol and ApoE are synthesised by the astrocytes and form the lipoprotein compound. These lipoproteins enter neurons through the neuronal surface receptors of the LDL-receptor related protein (LRP). Upon neuronal entry, the lysosome reacts with the lipoprotein and releases the free cholesterol from the neuron. Some of the free cholesterol reacts with the Cyp46 enzyme and forms the 24 hydroxycholesterol. The 24-hydroxycholesterol is then released from the neuron to enter the astrocytes and to be reconverted into cholesterol. The remaining free cholesterol released from neurons crosses the BBB into the peripheral blood circulation.

binding cassette $(\mathrm{ABC})$ transporter $\mathrm{ABCA} 1$ functions to secrete cholesterol from astrocytes and is an important regulator of cholesterol metabolism. In the brain, ABCA1 is also important for cholesterol trafficking, and its expression in cerebral endothelial cells can be stimulated by 24hydroxycholesterol, thus suggesting a role in the removal of excess brain cholesterol [157].

ABC transporters, particularly the ABCA1 transporter expressed in astrocytes, may also be of importance for shuttling cholesterol from glial cells to neurons. After cholesterol is synthesised in astrocytes, it is released through ABCA1 and packaged into lipoprotein particles resembling HDL, which in turn are then taken up into neurons through the recognition of ApoE by a variety of lipoprotein receptors such as LDLR, LRP and the ApoE receptor. The cholesterol is then oxidised into 24-hydroxycholesterol and 27hydroxycholesterol with the help of the enzymes CYP46 and CYP27. The 24-hydroxycholesterol is made by neurons within the brain [158-160]. In contrast, 27-hydroxycholesterol is produced by many cells, including neurons and oligodendrocytes. Cholesterol 24-hydroxylase, encoded by the CYP46 gene on chromosome 14, is expressed almost exclusively in the brain; only very low levels of its mRNA are found in other tissues such as the liver or testis. In the brain, CYP46 is expressed at especially high levels in neurons found in the cortex, hippocampus, dentate gyrus, thalamus and cerebellar Purkinje cells; however it does not appear to be expressed in glia [161]. CYP46 is a member of the cytochrome P450 family and is responsible for the catabolism of nearly all CNS cholesterol to 24hydroxycholesterol [162]. A portion of the FC reacts with CYP46 and is converted into 24-hydroxycholesterol in neurons, which can then re-enter the astrocytes for the recycling of cholesterol. The remaining excess cholesterol crosses the $\mathrm{BBB}$ and enters into the plasma, where it is eventually delivered to the liver for excretion into bile [163].

\section{APOE AND AD}

ApoE protein functions to maintain the synaptic integrity of neurons by stabilising the neuronal cytoskeleton, regulating intracellular $\mathrm{Ca}^{2+}$ levels and regulating the interaction among neurons, ECM and cholesterol. The largest production of ApoE is found in the liver, followed by the brain. In the brain, ApoE is predominantly secreted by astrocytes and microglia [164]. Abundant experimental studies have shown that ApoE influences the majority of the $\mathrm{AD}$ pathological processes such as $\mathrm{A} \beta$ generation or deposition, NFT formation, neuronal survival, lipid homeostasis and intracellular signalling [165]. There are three common human isoforms, namely ApoE2, ApoE3 and ApoE4, which arise from alleles E2, E3 and E4, respectively. ApoE3 is the most common isoform in the general population (77-78 \%), while ApoE2 is found in only 7-8 \% and ApoE4 is found in 14-16\% of individuals. ApoE4 is the strongest known risk factor for the development of SAD. The isoforms of ApoE influence $\mathrm{Ca}^{2+}$ channels differentially, resulting in different concentrations of free intracellular $\mathrm{Ca}^{2+}$. ApoE is also involved in various signalling pathways that 
coincide with the signalling pathways relevant to AD [166]. These pathways also affect the activities of kinases such as PKC, GSK-3 $\beta$, PKB/AKT, ERK, and JNK, as well as the transcriptional activity of CREB. The ApoE4 allele has also been associated with familial hypercholesterolaemia. The direct effect of hypercholesterolaemia on ApoE levels in the brain leads to an accumulation of $A \beta$. Neuronal ApoE receptors may also have a number of roles in APP trafficking and processing of $A \beta$ clearance [167]. Moreover, ApoE4 has been found to enhance the synthesis of $A \beta$ by promoting endocytotic recycling of APP. Findings obtained with the transgenic mouse model expressing human APPV717+/(PDAPP mice) suggest that ApoE4 contributes to the deposition of $A \beta$ [168]. Another in vivo study in transgenic mice showed that carboxy-terminal truncated ApoE stimulates Tau phosphorylation and intracellular formation of NFTs [169].

\section{CHOLESTEROL AND APP PROCESSING}

It has been shown that cholesterol accumulates in the dense cores of amyloid plaques. As a component of the cell membrane, cholesterol plays a major role in the metabolism of the single transmembrane protein APP and thus in the production of $A \beta$ [170]. Cholesterol is a major constituent of lipid rafts, together with sphingolipids (sphingomyelin and glycosphingolipids) and glycosylphosphatidylinositol (GPI)linked proteins. As several transmembrane receptors and cytoplasmic signalling molecules have been shown to concentrate to lipid rafts, they are considered functional hot spots of the plasma membrane. Lipid rafts are assembled in the Golgi complex and are constantly endocytosed. These lipid rafts appear to promote the accumulation of $A \beta$ and the initiation of $A \beta$ aggregation $[171,172]$. Increased cholesterol levels may lead to elevated membrane cholesterol, which would cause a change in membrane fluidity and lead to increased APP processing and $\mathrm{A} \beta$ production. In vitro studies suggest that increased plasma membrane fluidity may enhance APP/ $\alpha$-secretase interactions and $\alpha$-secretase enzymatic activity. In contrast, rigid cholesterol-enriched membranes may reduce APP/ $\alpha$-secretase interactions and promote $\beta$ - and $\gamma$ - secretase processing. The $\gamma$-secretase activity has been identified in cholesterol- and sphingolipidrich membrane microdomains known as lipid rafts. Cholesterol loading increases $\gamma$-secretase activity and results in enhanced release of amyloidogenic $\mathrm{A} \beta$ in vitro and in vivo. In transgenic mice over-expressing APP, a high cholesterol diet led to an increase in $A \beta$ and NPs and a decrease in $\operatorname{sAPP} \alpha$ [173-175].

In addition to the effect of cholesterol on membrane lipid ordering, sub-cellular distribution of cholesterol also regulates the proteolytic processing of APP [176, 177]. Unprocessed, mature APP is transported to the plasma membrane, where it undergoes further cholesterol-dependent processing. Partially matured APP is transported to the Golgi complex, where it completes maturation and is finally transported to the plasma membrane (Fig. 9). APP processing is thought to occur mostly in the trans-Golgi network, the plasma membrane, and the endosomes. In addition, A $\beta$ may be generated in the endo/lysosomal system from endocytosed APP. Intracellular cholesterol plays a critical role in $A \beta$ formation by directing the association of $\beta$-secretase with APP. Low intracellular cholesterol favours the processing of APP through the non-amyloidogenic pathway, leading to decreased $A \beta$ deposition. Newly synthesised APP is $\mathrm{N}$-glycosylated in the ER, the site of cholesterol esterification and hydroxylation. $\beta$ - and $\gamma$ secretase activities can be found in newly assembled cholesterol/sphingolipid-rich membrane microdomains in the Golgi [175, 178, 179].

The newly generated $A \beta$ is either released to the extracellular space or remains associated with the plasma membrane and lipid raft structures. Binding of $\mathrm{A} \beta$ to the cholesterol/sphingolipid-rich membrane microdomains (lipid rafts) strongly favours A $\beta$ aggregation [180]. Excess unesterified cholesterol in the plasma membrane and ER, as well as mitochondria-derived oxysterols, is loaded onto extracellular lipid acceptors such as ApoE by ABCA1. Monomeric $A \beta$ can bind to numerous molecules in the extracellular space. Binding of $A p o E$ to $A \beta$ regulates not only the aggregation but also the cellular uptake of $\mathrm{A} \beta$. ApoE-A $\beta$ complexes are taken up by the cells through receptor-mediated endocytosis mediated by LRP and LDLR. Lipoprotein-bound cholesteryl esters are hydrolysed in the endo/lysosomal system, and cholesterol is transported through Niemann-Pick disease, type 1 (NPC1)-containing compartment to the ER and Golgi. Endocytosed $A \beta$ also has access to other subcellular compartments through the vesicular transport system [181, 182].

\section{NGF AND THE HEART}

Neurotrophins (NTs) are small, highly basic proteins that are essential in the nervous system. They are capable of promoting neuronal cell survival or cell death depending on the environment. Alterations in the NT levels may underlie several medical conditions including pain, depression and obesity. Levels are also altered in disorders of nerve regeneration, learning and memory [183]. NTs have four distinct members: NGF, brain-derived neurotrophic factor (BDNF), NT-3 and NT-4/5. These NTs activate a family of receptor proteins, the TRK receptors. TRKA is primarily a receptor for NGF, TRKB is a receptor for BDNF and NT$4 / 5$, and TRKC is the specific receptor for NT-3. In addition to these specific receptors, all NTs bind to the p75NTR, a member of the TNFR superfamily [184].

NGF was the first nerve growth, survival and differentiation factor discovered, and it plays a crucial role in the sympathetic and sensory nervous systems. It regulates proliferation, differentiation and survival of various cell types of both the CNS and the PNS but also of cells of hematopoietic origin [17]. NGF signalling is mediated via binding to high and low affinity receptors. The high affinity receptor is TRKA, which transmits its signal via an internal tyrosine-kinase domain. The heart is innervated by sympathetic, parasympathetic and sensory nerve fibres expressing TRKA, which, together with the CNS, regulate cardiac functions. The efferent sympathetic and parasympathetic nervous system mediates the opposing neuronal regulation for inotropy and chronotropy of heart performance. NGF plays an important role in the maintenance and survival of such sympathetic neurons and a subset of sensory neurons during and after CNS and PNS development, although the survival of sensory neurons becomes independent of NGF in mature organisms [185]. 


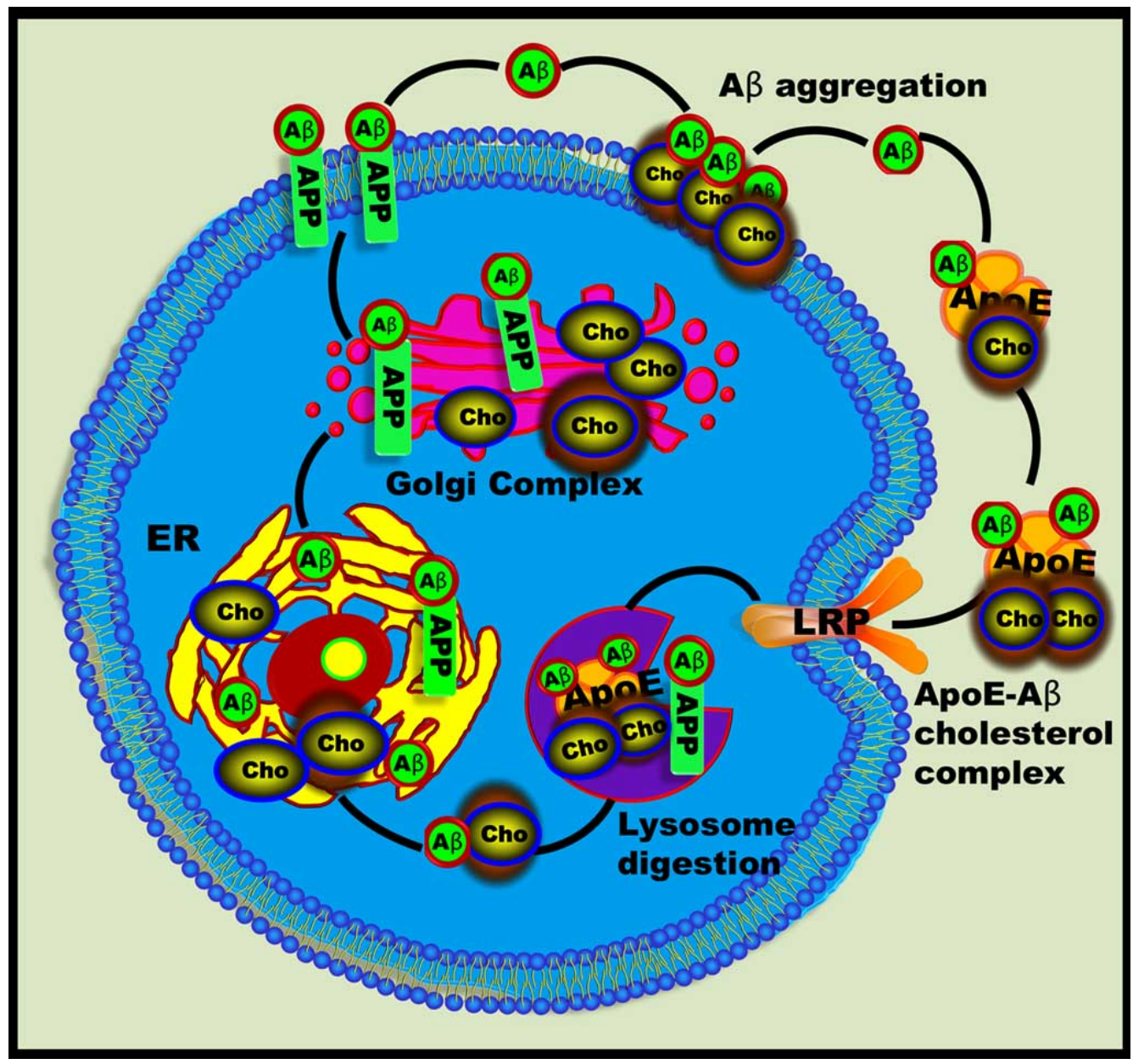

Fig. (9). Cholesterol and APP processing. Cholesterol plays a central role in APP metabolism and A $\beta$ synthesis. APP metabolism starts in the ER and then enters the Golgi complex and the plasma membrane. In the plasma membrane, A $\beta$ is released from APP. The free A $\beta$ binds with membrane-associated cholesterol, ultimately resulting in $A \beta$ aggregation. The remaining free $A \beta$ binds with $A p o E$ and the cholesterol complex to re-enter the cell through the LRP receptor system. This ApoE-A $\beta$ complex is degraded by lysosome enzymes to release the free cholesterol and $\mathrm{A} \beta$.

NGF in the sympathetic nervous system has been considered to function as a target-derived survival factor that is supplied in limited quantities by target organs, such as the heart, to regulate the final number of neurons and density of innervation [186]. In the NGF-null mouse, sympathetic ganglia are not present [187]. Conversely, cardiac-specific NGF over-expression in the mouse causes increased sympathetic innervation density and increased levels of norepinephrine stored in the dysfunctional heart [188, 189]. An influence of NGF on the sympathetic nervous system is also evident in adult animals. Injection of NGF into the left stellate ganglion over several weeks in dogs leads to pronounced sympathetic neuronal growth and nerve sprouting in the heart [190].

Myocardial NGF and sympathetic nerves of the heart appear to be linked in more ways than just neural support provided by the NGF. Once synaptic connections are established, NGF can potentiate synaptic transmission between sympathetic neurons and cardiac myocytes [191]. Modulation of these sympathetic synapses by NGF is acute and reversible and proves that synaptic potentiation works through a presynaptic mechanism. In addition to acute modulatory effects on synaptic efficacy, it has also been demonstrated that NGF produces a long-term enhancement of synaptic transmission of sympathetic neurons and cardiac myocytes [192]. Moreover, there is evidence of feedback inhibition of cardiac myocyte production of NGF at high levels of norepinephrine. The release of NGF by cultured cardiac myocytes is inhibited by norepinephrine, and chronic intravenous infusion of norepinephrine in dogs reduces myocardial NGF content [193]. High sympathetic tone in an innervated organ presumably inhibits its NGF production. This concept has been invoked to explain the concurrence in failing hearts of high sympathetic nerve firing rates, low NGF content and sympathetic neuronal rarefaction. Treatment of co-cultures of sympathetic neurons and cardiac myocytes with NGF, to preferentially activate neuronal TRKA, promotes the release of norepinephrine and increases the myocyte beat rate by fourfold [187]. In contrast, treatment with BDNF activates neuronal p75NTR, inducing the release of $\mathrm{ACh}$ and significantly slowing the rate of myocyte contraction [194]. These observations suggest that local secretion of NGF from cardiac myocytes and BDNF from the surrounding vasculature can rapidly exert opposing presynaptic actions to regulate heart rate and contractility. 
Thus, strategies to interfere with NGF-mediated TRKA activation and BDNF-mediated p75NTR activation may prove beneficial in reducing sympathetic neuron sprouting and norepinephrine release [195-197].

In congestive heart failure, NGF levels in the heart decrease as plasma norepinephrine levels rise; concomitantly, ET-1 plasma levels rise as well. However, it is still not clear how these changes are interrelated. Additionally, a recent report suggests that ET-1 overexpression in the adult mouse heart leads to dilated cardiomyopathy and death [198]. The complex interactions between myocytes and nerves in pathologic states provide insights into the disappointing results of ET-1 blockade in congestive heart failure and yield new pharmacologic targets for the future [199].

Thus, these studies indicate that NGF is involved in the regulation of myocardial performance and contributes to the maintenance of circulatory stability and cardiovascular homeostasis. They also indicate that acute coronary syndrome, atherosclerotic coronary arteries and ischaemic myocardium are characterised by altered circulating levels of NGF [200]. Furthermore, direct gene transfer of NGF into diabetic rat hearts improves silent myocardial ischaemia. Therefore, NGF-TRKA signalling might be a potential therapeutic target for sensory neuropathy in diabetic hearts [201, 202]. Taken together, these results suggest a novel role for NGF as a modulator of cardiac function and a potential link and biomarker for diabetic neuropathy and heart failure.

\section{ROLE OF NGF IN KIDNEY DEVELOPMENT AND DIABETIC NEPHROPATHY}

In the development of the kidney, mesenchymal and epithelial interactions play a significant role. Interactions between the epithelial ureter bud and the mesenchyme initiate the development of the metanephric kidney. The mesenchyme stimulates the ureter to grow and branch, allowing differentiation into the collecting ducts. In turn, the ureter induces a part of the mesenchyme to convert into new epithelium. Recently, receptors for growth factors were expressed focally in the interacting epithelium and mesenchyme [203]. NGF is critically involved in kidney development. p75NTR persists at a lower level in adults in glomeruli and a subpopulation of renal interstitial cells. It is expressed during later stages of glomerulogenesis, where it is limited to the mesangium [204]. A recent report showed that NGF and p75NTR are over-expressed in the kidneys of patients affected by various renal disorders, and it was hypothesised that this growth factor may be involved in the pathophysiology of inflammatory kidney diseases including diabetic nephropathy $[14,205]$. This hypothesis is also supported by the observation that NGF and its receptors are markedly expressed in renal disorders that are characterised by the enhanced presence of mast cells, macrophages and lymphocytes, cells that are known to produce and release NGF [17, 206].

\section{THE CONNECTION AMONG T2DM, CD, AD AND DEMENTIA}

Risk factors such as hypertension, T2DM and hypercholesterolaemia increase the risk of both VD and AD [207, 208]. VD is caused by decreased or interrupted circulation of the blood flow to parts of the brain, and it is predominantly caused by cerebrovascular diseases (CVD), $\mathrm{CD}$ or stroke. Among the cardiovascular risk factors related to $\mathrm{VD}$ are hypertension, atherosclerosis, CAD, T2DM and smoking. Risk factors for stroke do not independently contribute to dementia, but commonly occur in clusters of risk factors [209].

T2DM also contributes to microvascular changes in the brain, which in turn contribute to cognitive dysfunction and stroke [210-214]. Hyperglycaemia is generally accepted to be the major cause of diabetic microvascular complications and may play an important role in the development of macrovascular diseases. This condition allows cholesterol to build up in the walls of the blood vessels to form plaques that inhibit the heart-mediated oxygen and nutrition supply to various tissues and organs, including the brain [215]. The Framingham study also showed that the risk of developing congestive heart failure was increased in patients with T2DM and that the relative impact of diabetes on congestive heart failure was even greater than that for coronary heart disease [216].

Two major types of heart and blood vessel diseases common in people with diabetes are CAD and CVD. CAD is also called ischemic heart disease and is caused by the hardening or thickening of the blood vessel walls. The blood vessels are blocked by fatty deposits that reduce the blood supply to the heart, resulting in a heart attack. In contrast, $\mathrm{CD}$ affects blood flow to the brain, leading to the development of CVD and strokes. Brain cells are then deprived of oxygen and subsequently undergo apoptosis [217]. This decreased blood flow to the brain increases the risk of micro- and macrovascular diseases, which ultimately lead to dementia and stroke [218].

Hypertension is also associated with brain atrophy, large and small artery infarction and white matter lesion progression due to altered auto-regulation of blood flow to the brain. In ischaemic white matter lesions, long-term hypertension causes a narrowing of the lumen of the small arteries and arterioles that nourish the deep white matter. These vascular factors could directly affect the development of $\mathrm{AD}$ by causing neuronal death and the accumulation of plaques and tangles [219]. Small artery disease causes periventricular white matter ischaemia and lacunar strokes that manifest as VD [220].

Diabetes and ischaemic heart disease seem to enhance myocardial dysfunction, which leads to accelerated heart failure (diabetic cardiomyopathy). Thus, patients with diabetes are unusually prone to congestive heart failure. Several factors that probably underlie diabetic cardiomyopathy include severe coronary atherosclerosis, prolonged hypertension, chronic hyperglycaemia, microvascular disease, glycosylation of myocardial proteins and autonomic neuropathy [221]. Atherosclerosis is the major cause of dementia and increases the risk of AD. Thus, patients with diabetes often develop CD and CVD that in turn result in atherosclerosis which induces cerebral hypoperfusion, thus leading to cerebral hypoxia. These conditions destabilise synaptic connections and neuronal activity, gradually evolving into a neurodegenerative process characterised by the formation of SPs, NFTs and amyloid angiopathy as observed in VD or AD (Fig. 10) [222, 223]. 


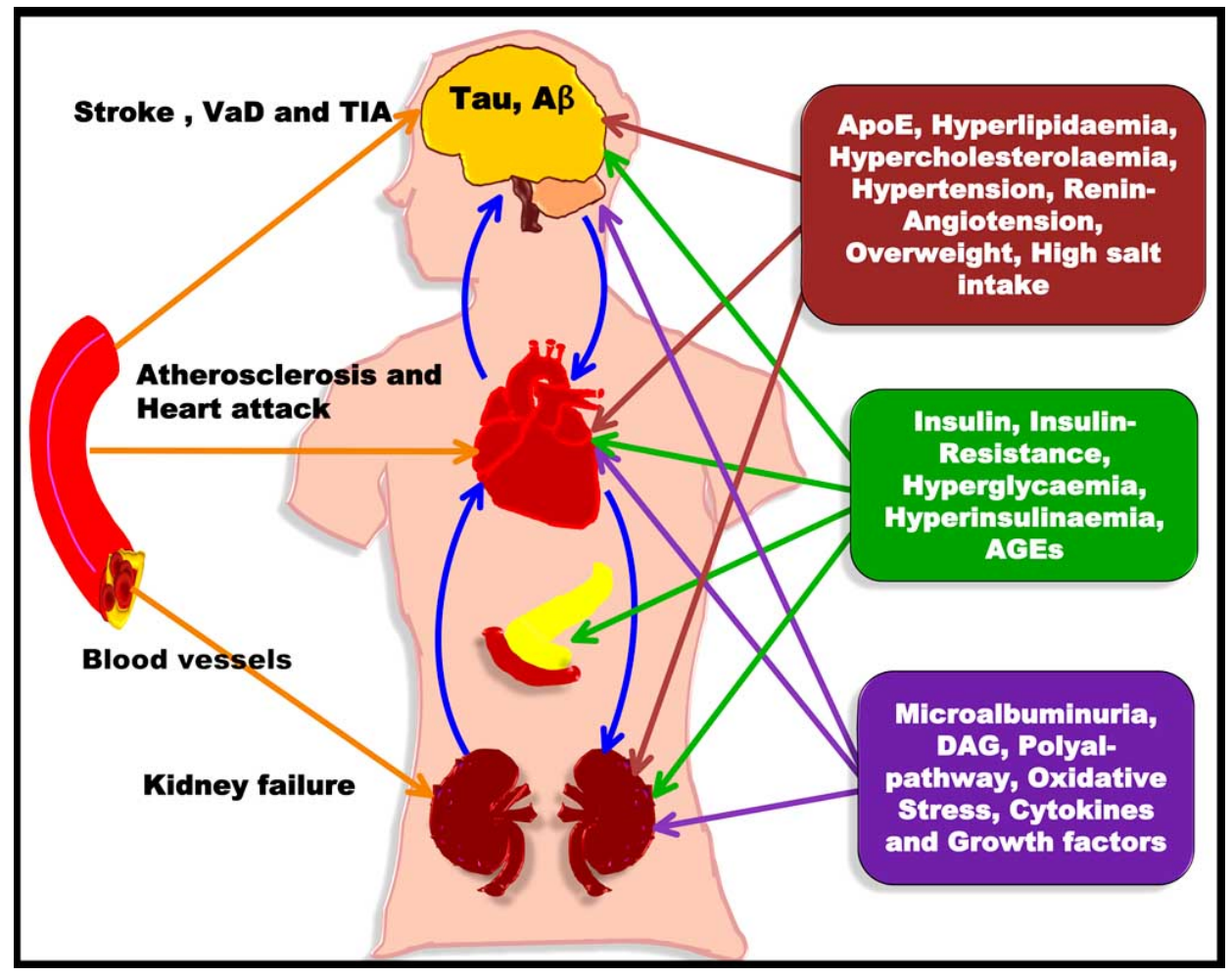

Fig. (10). Connection of T2DM, CAD, AD and Dementia. Blockage of heart vessels leads to atherosclerosis and heart attack, whereas blockage of the brain arteries results in VD and stroke.

\section{FUTURE DIRECTIONS AND TREATMENTS OF AD}

\section{Insulin-Degrading Enzyme (IDE) as a Therapeutic Target for the Treatment of AD}

Insulin is catabolised by IDE, which also degrades other compounds such as IGFI, IGFII, amylin, intra- and extracellular $A \beta$, glucagon, $\beta$-endorphin and dynorphins as well as the AICD fragment produced by the $\gamma$-secretase cleavage of APP [224, 225]. IDE is abundant in the cytosol and in peroxisomes. In addition, IDE is found in the rough ER (RER), the plasma membrane, and the extracellular environment. Increased brain levels of insulin should effectively inhibit the degradation of $A \beta$ by IDE. This would consequently enhance $\mathrm{A} \beta$ neurotoxicity and aid in $\mathrm{AD}$ progression [226]. IDE is part of the negative feedback loops that control insulin action. LRP and RAGE are involved in receptor-mediated flux of $A \beta$ across the BBB (Fig. 11). As mentioned earlier, LRP is a multifunctional signalling and scavenger receptor that consists of a heavy chain capable of binding a variety of ligands such as ApoE and a2macroglobulin $(\alpha 2 \mathrm{M}) . \alpha 2 \mathrm{M}$ is a protein that is capable of binding $\mathrm{A} \beta$ with high specificity and thus preventing its fibrillisation [227]. $\alpha 2 \mathrm{M}$ is found in neuritic plaques in $\mathrm{AD}$ brains and plays a major role in A $\beta$ clearance via LRP [228]. $\mathrm{A} \beta$ can be transported across the BBB and exported out of the brain into the bloodstream either by directly binding to LRP or by binding to the LRP ligands ApoE and $\alpha 2 \mathrm{M}$. While LRP appears to mediate the efflux of $A \beta$ from the brain to the periphery, RAGE has been strongly implicated in $A \beta$ influx into the CNS. Thus, soluble $A \beta$ can be removed from the brain via two fundamental pathways: either by enzymatic degradation (for instance via IDE) or by receptormediated clearance via LRP [229]. Once A $\beta$ crosses the $\mathrm{BBB}$ and enters the bloodstream, it can re-enter the brain via the RAGE receptor or be delivered to peripheral sites for degradation in the liver or kidney. Consequently, clearance of $A \beta$ from the brain is a therapeutic approach and can be considered for the prevention of AD [230-232].

\section{ACYL-COA: CHOLESTEROL ACYLTRANSFERASE (ACAT) AS A THERAPEUTIC APPROACH FOR AD}

ACAT is a protein that converts cholesterol to highly insoluble CEs. ACAT is essential for the regulation of intracellular cholesterol homoeostasis and the distribution of cholesterol throughout the body. ACAT is the enzyme that removes excess cholesterol from membranes and converts FC to CEs for storage purposes. ACAT has two different isoforms: ACAT1 and ACAT2. In human tissues, ACAT1 is expressed ubiquitously, with prominent protein expression in Kupffer cells (located in the liver) and macrophages, as well as neurons [233]. Expression of ACAT2 appears to be restricted to the liver and intestine, where it is hypothesised to be a major player in the responsiveness to dietary cholesterol. Elevated FC results in the activation of ACAT and the production of CE. A close relationship exists among ACAT, intracellular cholesterol trafficking, and the sterol regulatory element binding protein (SREBP) pathway. SREBP consists of a complex group of membrane proteins that regulate cholesterol homeostasis. ACAT keeps the levels of FC in the membrane under strict control [234]. This pool of FC ultimately regulates the SREBP pathway. In the brain, cholesterol can be either stored within the cell as FC or 


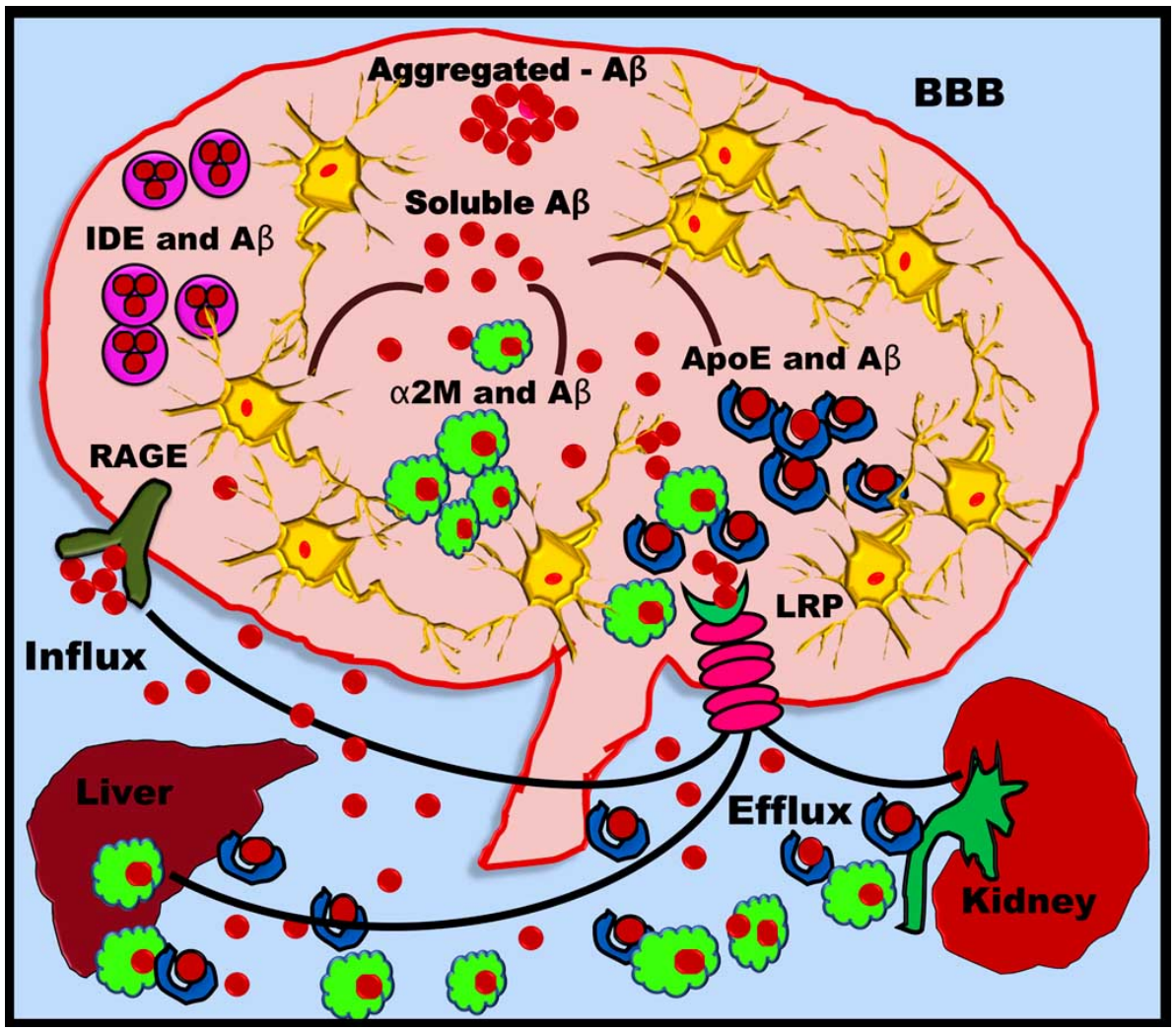

Fig. (11). IDE as a therapeutic approach for AD. A $\beta$ is degraded by ApoE, IDE and $\alpha 2 \mathrm{M}$. A $\beta$ binds to IDE, which allows its degradation inside the CNS. The remaining A $\beta$ binds ApoE and $\alpha 2 \mathrm{M}$ that pass through the BBB via LRP. A portion of soluble A $\beta$ can also efflux from the LRP to re-enter the brain via RAGE. The peripheral ApoE-A $\beta$ and $\alpha 2 \mathrm{M}-\mathrm{A} \beta$ complexes enter the liver and kidney, where they are degraded.

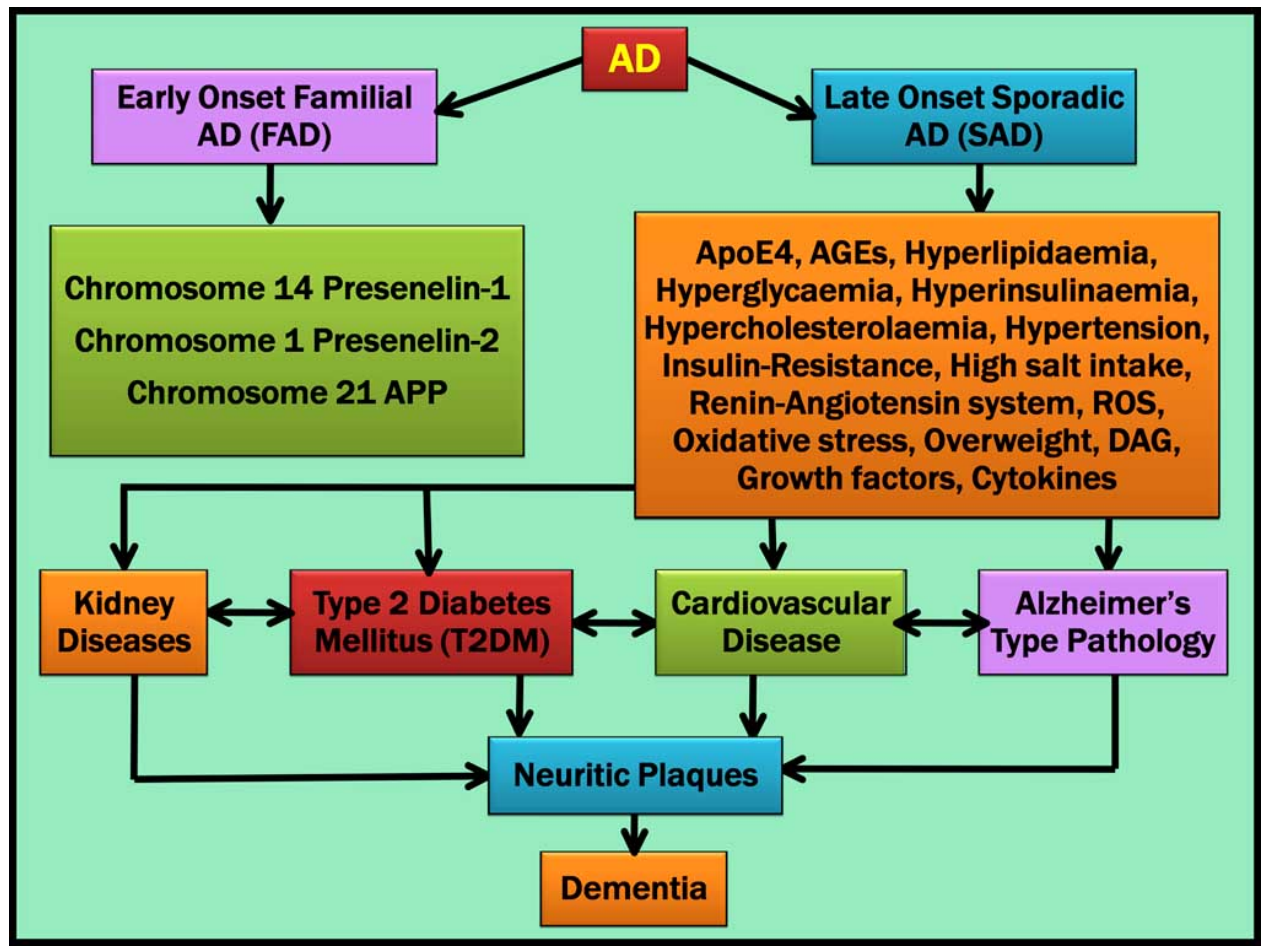

Fig. (12). AD is classified into two types, FAD and SAD. FAD is based on mutations in specific genes such as PS1, PS2 and APP, whereas SAD is based on various factors including hypercholesterolaemia, hyperglycaemia, and insulin resistance. These SAD factors lead to the formation of T2DM, cardiovascular diseases, kidney diseases, and ultimately neurovascular dementia, such as AD.

converted into CEs and stored in cytoplasmic droplets. An increase in the intracellular levels of CE leads to increased
$\mathrm{A} \beta$ production, whereas inhibition of ACAT leads to decreased levels of CEs and increased intracellular FC. The 
latter sequence eventually leads to decreased $\mathrm{A} \beta$ production. Thus, ACAT is also particularly important in the process of AD development. Pharmacological inhibitors of ACAT are available, and these inhibitors could reduce $A \beta$ production to decrease amyloid plaque formation in $\operatorname{AD}[235,236]$.

\section{STATIN AS A THERAPEUTIC APPROACH FOR AD}

Cholesterol synthesis in neurons is regulated by HMG$\mathrm{CoA}$ reductase. HMG-CoA reductase inhibitors are commonly known as statins. Different types of available statins include lovastatin (Mevacer), pravastatin (Prasiocor), simvastatin (Zocor), rosuvastatin (Crestor) and atorvastatin (Lipitor) [237, 238]. These statins competitively inhibit HMG-CoA reductase, which is a rate-limiting enzyme that catalyses the conversion of HMG-CoA to L-mevalonate, and reduce the formation of L-mevalonate. The latter is a key intermediate in cholesterol synthesis and aids in decreasing LDL cholesterol and increasing HDL cholesterol levels [239, 240]. Statins inhibit both cholesterol and isoprenoid synthesis; therefore, it is important to determine their individual effects on APP processing [155, 241, 242]. The variable side chain of a statin determines its solubility across the BBB. Atorvastatin, lovastatin and simvastatin are lipophilic and cross into the brain readily, whereas cerivastatin (Baycol, Lipobay (removed from market)), fluvastatin (Lescol, Canef, Vastin) and pravastatin are hydrophilic and do not cross. Statin inhibitors also inhibit isoprenylation, which results in a reduction of membrane raft clustering involved in APP processing and A $\beta$ degradation [243, 244].

\section{CONCLUSION}

The parallel development of T2DM and CD is a compound risk factor for both VD and AD [245]. There are strong additional interactions with other risk factors, such as hypertension, hyperglycaemia and hyperinsulinaemia, hypercholesterolaemia, hyperlipidaemia, endothelial dysfunction, AGE formation and the ApoE4 genotype. A specific role of NGF as potential link (biomarker?) of these diseases, however, remains elusive $[15,17,246]$. Disturbances in insulin signalling pathways may contribute to cognitive decline such as that seen with AD [247]. The link among insulin resistance, cholesterol metabolism, CD and VD has opened a new arena for research in the field of cognitive functions affected by aging and related neurodegenerative diseases.

\section{ABBREVIATIONS}

$\begin{array}{ll}\text { ABCA1 } & =\text { ATP-binding cassette transporter A1 } \\ \text { ACAT } & =\text { Acyl-CoA: Cholesterol acyltransferase } \\ \text { ACE } & =\text { Acetylcholinesterase } \\ \text { AD } & =\text { Alzheimer's disease } \\ \text { AGE } & =\text { Advance glycation end products } \\ \text { ApoE } & =\text { Apolipoprotein E } \\ \text { APP } & =\text { Amyloid precursor protein } \\ \text { ATP } & =\text { Adenosine triphosphate } \\ \text { A } \beta & =\text { Amyloid beta peptide } \\ \text { BACE } & =\beta \text {-site APP cleaving enzyme }\end{array}$

\begin{tabular}{|c|c|}
\hline BAD & $=\mathrm{Bcl}-2$ associated death protein \\
\hline $\mathrm{BBB}$ & $=$ Blood-brain barrier \\
\hline bFGF & $=$ Basic fibroblast growth factor \\
\hline CAD & $=$ Coronary artery disease \\
\hline $\mathrm{CD}$ & $=$ Cardiovascular disease \\
\hline $\mathrm{CE}$ & $=$ Cholesterol esters \\
\hline CNS & $=$ Central nervous system \\
\hline CREB & $=\mathrm{cAMP}$ responsive element-binding protein \\
\hline CSF & $=$ Cerebrospinal fluid \\
\hline CTGF & $=$ Ciliary transcription growth factor \\
\hline CVD & $=$ Cerebrovascular disease \\
\hline DAG & $=$ Diacylglycerol \\
\hline DMPP & $=$ Dimethylallyl pyrophosphate \\
\hline $\mathrm{DN}$ & $=$ Diabetic nephropathy \\
\hline DPN & $=$ Diabetic peripheral neuropathy \\
\hline ECM & $=$ Extracellular matrix \\
\hline EGF & $=$ Epidermal growth factor \\
\hline ER & $=$ Endoplasmic reticulum \\
\hline ERK & $=$ Extracellular signal regulated kinase \\
\hline FAD & $=$ Familial Alzheimer's disease \\
\hline $\mathrm{FC}$ & $=$ Free cholesterol \\
\hline FPP & $=$ Farnesyl pyrophosphate \\
\hline GLUT & $=$ Glucose transporter \\
\hline GPP & $=$ Geranyl pyrophosphate \\
\hline Grb2 & $=$ Growth factor receptor-binding protein 2 \\
\hline GSK- $3 \alpha / \beta$ & $=$ Glycogen synthase kinase $-3 \alpha / \beta$ \\
\hline HDL & $=$ High density lipoprotein \\
\hline IDDM & $=$ Insulin dependent diabetes mellitus \\
\hline IDE & $=$ Insulin degrading enzyme \\
\hline IGF & $=$ Insulin-like growth factor \\
\hline IL-1 $\beta$ & $=$ Interleukin $-1 \beta$ \\
\hline IPP & $=$ Isopentenyl pyrophosphate \\
\hline IR & $=$ Insulin resistance \\
\hline IRS & $=$ Insulin receptor substrate \\
\hline JNK & $=$ Jun-N-terminal kinase \\
\hline LDL & $=$ Low density lipoprotein \\
\hline LDLR & $=$ Low density lipoprotein receptor \\
\hline LOAD & $=$ Late onset of Alzheimer's disease \\
\hline LRP & $=\mathrm{LDL}$ receptor related protein \\
\hline MAP & $=$ Microtubule associated protein \\
\hline MAPK & $=$ Mitogen activated protein kinase \\
\hline $\mathrm{NF}-\kappa \mathrm{B}$ & $=$ Nuclear factor $-\kappa B$ \\
\hline NFTs & $=$ Neurofibrillary tangles \\
\hline
\end{tabular}




$$
\begin{aligned}
& \text { NGF } \quad=\text { Nerve growth factor } \\
& \text { NIDDM = Non insulin dependent diabetes mellitus } \\
& \text { NIRKO = Neuronal insulin receptor knockout mice } \\
& \text { NP } \quad=\text { Neurofibrillary plaques } \\
& \text { p75NTR }=\mathrm{p} 75 \text { neurotrophin receptor } \\
& \mathrm{PAD}=\text { Peripheral arterial disease } \\
& \text { PDGF } \quad=\text { Platelet-derived growth factor } \\
& \text { PI3K = Phosphoinositide-3 kinase } \\
& \mathrm{PKB}=\text { Protein kinase } \mathrm{B} / \mathrm{Akt} \\
& \mathrm{PKC}=\text { Protein kinase } \mathrm{C} \\
& \text { PLC = Phospholipase } \mathrm{C} \\
& \text { PS1 }=\text { Presenilin } 1 \\
& \text { PS2 }=\text { Presenilin } 2 \\
& \text { RAGE } \quad=\text { Receptor of advanced glycation end products } \\
& \text { ROS }=\text { Reactive oxygen species } \\
& \text { SAD }=\text { Sporadic Alzheimer's disease } \\
& \text { SH2 }=\text { Src homology } 2 \\
& \text { SOS }=\text { Son of sevenless } \\
& \mathrm{SP}=\text { Senile plaque } \\
& \text { SREBP }=\text { Sterol regulatory element binding protein } \\
& \text { T1DM = Type } 1 \text { diabetes mellitus } \\
& \text { T2DM = Type } 2 \text { diabetes mellitus } \\
& \text { TGF- } \alpha / \beta=\text { Transcription growth factor }-\alpha / \beta \\
& \text { TIA }=\text { Transient ischaemic attacks } \\
& \text { TRK }=\text { Tyrosine receptor kinase } \\
& \text { VD } \quad=\text { Vascular dementia } \\
& \text { VEGF }=\text { Vascular endothelial growth factor } \\
& \text { VLDL = Very low density lipoprotein } \\
& \alpha 2 \mathrm{M}=\alpha 2 \text {-Macroglobulin }
\end{aligned}
$$

\section{REFERENCES}

[1] Graff-Radford, N.R.; Crook, J.E.; Lucas, J.; Boeve, B.F.; Knopman, D.S.; Ivnik, R.J.; Smith, G.E.; Younkin, L.H.; Petersen, R.C.; Younkin, S.G. Association of low plasma Abeta42/Abeta40 ratios with increased imminent risk for mild cognitive impairment and Alzheimer disease. Arch. Neurol., 2007, 64, 354-62.

[2] Hock, C.; Heese, K.; Muller-Spahn, F.; Hulette, C.; Rosenberg, C.; Otten, U. Decreased trkA neurotrophin receptor expression in the parietal cortex of patients with Alzheimer's disease. Neurosci. Lett., 1998, 241, 151-4.

[3] Hock, C.H.; Heese, K.; Olivieri, G.; Hulette, C.H.; Rosenberg, C.; Nitsch, R.M.; Otten, U. Alterations in neurotrophins and neurotrophin receptors in Alzheimer's disease. J. Neural. Transm. Suppl., 2000, 59, 171-4.

[4] Hock, C.; Heese, K.; Hulette, C.; Rosenberg, C.; Otten, U. Regionspecific neurotrophin imbalances in Alzheimer disease: decreased levels of brain-derived neurotrophic factor and increased levels of nerve growth factor in hippocampus and cortical areas. Arch. Neurol., 2000, 57, 846-51.

[5] Ieda, M.; Kanazawa, H.; Ieda, Y.; Kimura, K.; Matsumura, K.; Tomita, Y.; Yagi T, Onizuka T, Shimoji K, Ogawa S, Makino S, Sano M, Fukuda K. Nerve growth factor is critical for cardiac sensory innervation and rescues neuropathy in diabetic hearts. Circulation, 2006, 114, 2351-63.
[6] Xu, W.L.;Qiu, C.X.; Wahlin, A.; Winblad, B.; Fratiglioni, L. Diabetes mellitus and risk of dementia in the Kungsholmen project: a 6-year follow-up study. Neurology, 2004, 63, 1181-6.

[7] Li, L.; Holscher, C. Common pathological processes in Alzheimer disease and type 2 diabetes: a review. Brain Res. Rev., 2007, 56, 384-402.

[8] Hulette, C.M.; Welsh-Bohmer, K. Coronary artery disease is associated with Alzheimer disease neuropathology in APOE4 carriers. Neurology, 2007, 68, 471; author reply

[9] Qiu, C.; Winblad, B.; Marengoni, A.; Klarin, I.; Fastbom, J.; Fratiglioni, L. Heart failure and risk of dementia and Alzheimer disease: a population-based cohort study. Arch. Intern. Med., 2006, 166, 1003-8.

[10] Bergmann, C.; Sano, M. Cardiac risk factors and potential treatments in Alzheimer's disease. Neurol. Res., 2006, 28, 595-604.

[11] Wolozin, B.; Bednar, M.M. Interventions for heart disease and their effects on Alzheimer's disease. Neurol. Res., 2006, 28, 630-6.

[12] Polidori, M.C.; Mariani, E.; Mecocci, P.; Nelles, G. Congestive heart failure and Alzheimer's disease. Neurol. Res., 2006, 28, 58894.

[13] de la Torre, J.C. Cerebrovascular and cardiovascular pathology in Alzheimer's disease. Int. Rev. Neurobiol., 2009, 84, 35-48.

[14] Heese, K.; Beck, K.F.; Behrens, M.H.; Pluss, K.; Fierlbeck, W.; Huwiler, A.; Mühl, H.; Geiger, H.; Otten, U.; Pfeilschifter, J. Effects of high glucose on cytokine-induced nerve growth factor (NGF) expression in rat renal mesangial cells. Biochem. Pharmacol., 2003, 65, 293-301.

[15] Heese, K.; Akatsu, H. Alzheimer's disease--an interactive perspective. Curr. Alzheimer Res., 2006, 3,109-21.

[16] Otten, U.; Marz, P.; Heese, K.; Hock, C.; Kunz, D.; Rose-John, S. Cytokines and neurotrophins interact in normal and diseased states. Ann. N.Y. Acad. Sci., 2000, 917, 322-30.

[17] Ayyadhury, S.; Heese, K. Neurotrophins - more than neurotrophic. Curr. Immunol. Rev., 2007, 3,189-215.

[18] Selkoe, D.J. Alzheimer's disease: genes, proteins, and therapy. Physiol. Rev., 2001, 81, 741-66.

[19] Blennow, K.; de Leon, M.J.; Zetterberg, H. Alzheimer's disease. Lancet, 2006, 368, 387-403.

[20] Maurer, K.; Hoyer, S. Alois Alzheimer revisited: differences in origin of the disease carrying his name. J. Neural. Transm., 2006, $113,1645-58$.

[21] Mott, R.T.; Hulette, C.M. Neuropathology of Alzheimer's disease. Neuroimaging Clin. N. Am., 2005, 15, 755-65, ix.

[22] Myers, A.J.; Goate, A.M. The genetics of late-onset Alzheimer's disease. Curr. Opin. Neurol., 2001, 14, 433-40.

[23] Suh, Y.H.; Checler, F. Amyloid precursor protein, presenilins, and alpha-synuclein: molecular pathogenesis and pharmacological applications in Alzheimer's disease. Pharmacol. Rev., 2002, 54, 469-525.

[24] Selkoe, D.J. Biochemistry and molecular biology of amyloid betaprotein and the mechanism of Alzheimer's disease. Handb. Clin. Neurol., 2008, 89, 245-60.

[25] Schenk, D. Alzheimer's disease. A partner for presenilin. Nature, 2000, 407, 34-5.

[26] St George-Hyslop, P.H. Molecular genetics of Alzheimer's disease. Biol. Psychiatry, 2000, 47, 183-99.

[27] Contestabile, A.; Ciani, E. The place of choline acetyltransferase activity measurement in the "cholinergic hypothesis" of neurodegenerative diseases. Neurochem. Res., 2008, 33, 318-27.

[28] Hardy, J.; Selkoe, D.J. The amyloid hypothesis of Alzheimer's disease: progress and problems on the road to therapeutics. Science, 2002, 297, 353-6.

[29] Caccamo, A.; Fisher, A.; LaFerla, F.M. M1 agonists as a potential disease-modifying therapy for Alzheimer's disease. Curr. Alzheimer Res., 2009, 6, 112-7.

[30] Pepeu, G.; Giovannini, M.G. Cholinesterase inhibitors and beyond. Curr. Alzheimer Res., 2009, 6, 86-96.

[31] Buckingham, S.D.; Jones, A.K.; Brown, L.A.; Sattelle, D.B. Nicotinic acetylcholine receptor signalling: roles in Alzheimer's disease and amyloid neuroprotection. Pharmacol. Rev., 2009, 61, 39-61.

[32] Mattson, M.P. Cellular actions of beta-amyloid precursor protein and its soluble and fibrillogenic derivatives. Physiol. Rev., 1997, 77, 081-132.

[33] Avila, J. Tau protein, the main component of paired helical filaments. J. Alzheimers Dis., 2006, 9, 171-5. 
[34] Wang, J.Z.; Liu, F. Microtubule-associated protein tau in development, degeneration and protection of neurons. Prog. Neurobiol., 2008, 85, 148-75.

[35] Spires-Jones, T.L.; Stoothoff, W.H.; de Calignon, A.; Jones, P.B.; Hyman, B.T. Tau pathophysiology in neurodegeneration: a tangled issue. Trends Neurosci., 2009, 32, 150-9.

[36] Lace, G.L.; Wharton, S.B.; Ince, P.G. A brief history of tau: the evolving view of the microtubule-associated protein tau in neurodegenerative diseases. Clin. Neuropathol., 2007, 26, 43-58.

[37] Iqbal, K.; Novak, M. From tangles to tau protein. Bratisl. Lek. Listy, 2006, 107, 341-2.

[38] Lee, V.M. Biomedicine. Tauists and beta-aptists united--well almost. Science, 2001, 293, 1446-7.

[39] Iwata, N.; Higuchi, M.; Saido, T.C. Metabolism of amyloid-beta peptide and Alzheimer's disease. Pharmacol. Ther., 2005, 108, 129-48.

[40] Goedert, M.; Klug, A.; Crowther, R.A. Tau protein, the paired helical filament and Alzheimer's disease. J. Alzheimers Dis., 2006, 9, 195-207.

[41] Strong, M.J.; Yang, W.; Strong, W.L.; Leystra-Lantz, C.; Jaffe, H.; Pant, H.C. Tau protein hyperphosphorylation in sporadic ALS with cognitive impairment. Neurology, 2006, 66, 1770-1.

[42] Bayer, T.A.; Wirths, O, Majtenyi, K.; Hartmann, T.; Multhaup, G.; Beyreuther, K.; Czech, C. Key factors in Alzheimer's disease: betaamyloid precursor protein processing, metabolism and intraneuronal transport. Brain Pathol., 2001, 11, 1-11.

[43] Selkoe, D.J.; Schenk, D. Alzheimer's disease: molecular understanding predicts amyloid-based therapeutics. Annu. Rev. Pharmacol. Toxicol., 2003, 43, 545-84.

[44] Vassar, R.; Bennett, B.D.; Babu-Khan, S.; Kahn, S.; Mendiaz, E.A.; Denis, P.; Denis, P.; Teplow, D.B.; Ross, S.; Amarante, P.; Loeloff, R.; Luo, Y.; Fisher, S.; Fuller, J.; Edenson, S.; Lile, J.; Jarosinski, M.A.; Biere, A.L.; Curran, E.; Burgess, T.; Louis, J.C.; Collins, F.; Treanor, J.; Rogers, G.; Citron, M. Beta-secretase cleavage of Alzheimer's amyloid precursor protein by the transmembrane aspartic protease BACE. Science, 1999, 286, 73541.

[45] Wolfe, M.S.; Guenette, S.Y. APP at a glance. J. Cell Sci., 2007, 120, 3157-61.

[46] Avery, L. Diabetes mellitus types 1 and 2: an overview. Nurs. Stand, 1998, 13, 35-8.

[47] Chillaron, J.J.; Goday, A.; Pedro-Botet, J. Metabolic syndrome, type 1 diabetes mellitus and insulin resistance. Med. Clin. (Barc), 2008, 130, 466-70.

[48] Martin, B.C.; Warram, J.H.; Krolewski, A.S.; Bergman, R.N.; Soeldner, J.S.; Kahn, C.R. Role of glucose and insulin resistance in development of type 2 diabetes mellitus: results of a 25-year follow-up study. Lancet, 1992, 340, 925-9.

[49] Muoio, D.M.; Newgard, C.B. Mechanisms of disease: molecular and metabolic mechanisms of insulin resistance and beta-cell failure in type 2 diabetes. Nat. Rev. Mol. Cell Biol., 2008, 9, 193205.

[50] Kahn, B.B.; Flier, J.S. Obesity and insulin resistance. J. Clin. Invest., 2000, 106, 473-81.

[51] Lawrence, M.C.; McKern, N.M.; Ward, C.W. Insulin receptor structure and its implications for the IGF-1 receptor. Curr. Opin. Struct. Biol., 2007, 17, 699-705.

[52] Youngren, J.F. Regulation of insulin receptor function. Cell Mol. Life Sci., 2007, 64, 873-91.

[53] Goren, H.J. Role of insulin in glucose-stimulated insulin secretion in beta cells. Curr. Diabetes Rev., 2005, 1, 309-30.

[54] MacDonald, P.E.; Joseph, J.W.; Rorsman, P. Glucose-sensing mechanisms in pancreatic beta-cells. Philos. Trans. R. Soc. Lond. B. Biol. Sci., 2005, 360, 2211-25.

[55] Gerozissis, K. Brain insulin and feeding: a bi-directionl communication. Eur. J. Pharmacol., 2004, 490, 59-70.

[56] Barros, L.F.; Bittner, C.X.; Loaiza, A.; Porras, O.H. A quantitative overview of glucose dynamics in the gliovascular unit. Glia, 2007, 55, 1222-37.

[57] Bell, G.I.; Kayano, T.; Buse, J.B.; Burant, C.F.; Takeda, J.; Lin, D.; et al. Molecular biology of mammalian glucose transporters. Diabetes Care, 1990, 13,198-208.

[58] Simpson, I.A.; Carruthers, A.; Vannucci, S.J. Supply and demand in cerebral energy metabolism: the role of nutrient transporters. $J$. Cereb. Blood Flow. Metab., 2007, 27, 1766-91.
[59] Mueckler, M. Facilitative glucose transporters. Eur. J. Biochem., 1994, 219, 713-25.

[60] Marshall, B.A.; Mueckler, M.M. Differential effects of GLUT-1 or GLUT-4 overexpression on insulin responsiveness in transgenic mice. Am. J. Physiol., 1994, 267, E738-44.

[61] Ngarmukos, C.; Baur, E.L.; Kumagai, A.K. Co-localization of GLUT1 and GLUT4 in the blood-brain barrier of the rat ventromedial hypothalamus. Brain Res., 2001, 900, 1-8.

[62] Livingstone, C.; Lyall, H.; Gould, G.W. Hypothalamic GLUT 4 expression: a glucose- and insulin-sensing mechanism? Mol. Cell Endocrinol., 1995, 107, 67-70.

[63] Sankar, R.; Thamotharan, S.; Shin, D.; Moley, K.H.; Devaskar, S.U. Insulin-responsive glucose transporters-GLUT8 and GLUT4 are expressed in the developing mammalian brain. Brain Res. Mol. Brain Res., 2002, 107, 157-65.

[64] Simpson, I.A.; Appel, N.M.; Hokari, M.; Oki, J.; Holman, G.D.; Maher, F.; Koehler-Stec, E.M.; Vannucci, S.J.; Smith, Q.R. Bloodbrain barrier glucose transporter: effects of hypo- and hyperglycemia revisited. J. Neurochem., 1999, 72, 238-47.

[65] Biessels, G.J.; Bravenboer, B.; Gispen, W.H. Glucose, insulin and the brain: modulation of cognition and synaptic plasticity in health and disease: a preface. Eur. J. Pharmacol., 2004, 490, 1-4.

[66] Banks, W.A. The source of cerebral insulin. Eur. J. Pharmacol., 2004, 490, 5-12.

[67] Cheng, C.M.; Reinhardt, R.R.; Lee, W.H.; Joncas, G.; Patel, S.C.; Bondy, C.A. Insulin-like growth factor 1 regulates developing brain glucose metabolism. Proc. Natl. Acad. Sci. USA, 2000, 97, 10236-41.

[68] Aleman, A.; Torres-Aleman, I. Circulating insulin-like growth factor I and cognitive function: Neuromodulation throughout the lifespan. Prog. Neurobiol., 2009, 89(3), 256-265.

[69] Laron, Z. Insulin and the brain. Arch. Physiol. Biochem., 2009 115, 112-6.

[70] Steen, E.; Terry, B.M.; Rivera, E.J.; Cannon, J.L.; Neely, T.R.; Tavares, R.; Xu, X.J.; Wands, J.R.; de la Monte, S.M. Impaired insulin and insulin-like growth factor expression and signaling mechanisms in Alzheimer's disease--is this type 3 diabetes? $J$. Alzheimers Dis., 2005, 7,63-80.

[71] Collett-Solberg, P.F.; Cohen, P. Genetics, chemistry, and function of the IGF/IGFBP system. Endocrine, 2000, 12, 121-36.

[72] Bondy, C.A.; Cheng, C.M. Signaling by insulin-like growth factor 1 in brain. Eur. J. Pharmacol., 2004, 490, 25-31.

[73] Qiu, W.Q.; Folstein, M.F. Insulin, insulin-degrading enzyme and amyloid-beta peptide in Alzheimer's disease: review and hypothesis. Neurobiol. Aging, 2006, 27, 190-8.

[74] Freude, S.; Schilbach, K.; Schubert, M. The role of IGF-1 receptor and insulin receptor signaling for the pathogenesis of Alzheimer's disease: from model organisms to human disease. Curr. Alzheimer Res., 2009, 6, 213-23.

[75] Plum, L.; Schubert, M.; Bruning, J.C. The role of insulin receptor signaling in the brain. Trends Endocrinol. Metab., 2005, 16, 59-65.

[76] Zhao, W.; Chen, H.; Quon, M.J.; Alkon, D.L. Insulin and the insulin receptor in experimental models of learning and memory. Eur. J. Pharmacol., 2004, 490, 71-81.

[77] Lizcano, J.M.; Alessi, D.R. The insulin signalling pathway. Curr. Biol., 2002, 12, R236-8.

[78] Iqbal, K.; Grundke-Iqbal, I. Metabolic/signal transduction hypothesis of Alzheimer's disease and other tauopathies. Acta Neuropathol., 2005, 109, 25-31.

[79] Phiel, C.J.; Wilson, C.A.; Lee, V.M.; Klein, P.S. GSK-3alpha regulates production of Alzheimer's disease amyloid-beta peptides. Nature, 2003, 423, 435-9.

[80] Folli, F.; Ghidella, S.; Bonfanti, L.; Kahn, C.R.; Merighi, A. The early intracellular signaling pathway for the insulin/insulin-like growth factor receptor family in the mammalian central nervous system. Mol. Neurobiol., 1996, 13, 155-83.

[81] Frolich, L.; Blum-Degen, D.; Bernstein, H.G.; Engelsberger, S.; Humrich, J.; Laufer, S.; et al. Brain insulin and insulin receptors in aging and sporadic Alzheimer's disease. J. Neural. Transm., 1998, 105, 423-38.

[82] Folli, F.; Bonfanti, L.; Renard, E.; Kahn, C.R.; Merighi, A. Insulin receptor substrate-1 (IRS-1) distribution in the rat central nervous system. J. Neurosci., 1994, 14, 6412-22.

[83] Moloney, A.M.; Griffin, R.J.; Timmons, S.; O'Connor, R.; Ravid, R.; O'Neill, C. Defects in IGF-1 receptor, insulin receptor and IRS- 
$1 / 2$ in Alzheimer's disease indicate possible resistance to IGF-1 and insulin signalling. Neurobiol. Aging, 2010, 31(2), 224-243.

[84] Shineman, D.W.; Dain, A.S.; Kim, M.L.; Lee, V.M. Constitutively active Akt inhibits trafficking of amyloid precursor protein and amyloid precursor protein metabolites through feedback inhibition of phosphoinositide 3-kinase. Biochemistry, 2009, 48, 3787-94.

[85] Carro, E.; Trejo, J.L.; Spuch, C.; Bohl, D.; Heard, J.M.; TorresAleman, I. Blockade of the insulin-like growth factor I receptor in the choroid plexus originates Alzheimer's-like neuropathology in rodents: new cues into the human disease? Neurobiol. Aging, 2006, 27, 1618-31.

[86] Carro, E.; Trejo, J.L.; Gomez-Isla, T.; LeRoith, D.; Torres-Aleman, I. Serum insulin-like growth factor I regulates brain amyloid-beta levels. Nat. Med., 2002, 8, 1390-7.

[87] Niikura, T.; Hashimoto, Y.; Okamoto, T.; Abe, Y.; Yasukawa, T.; Kawasumi, M.; Hiraki, T.; Kita, Y.; Terashita, K.; Kouyama, K.; Nishimoto, I. Insulin-like growth factor I (IGF-I) protects cells from apoptosis by Alzheimer's V642I mutant amyloid precursor protein through IGF-I receptor in an IGF-binding protein-sensitive manner. J. Neurosci., 2001, 21, 1902-10.

[88] Puglielli, L. Aging of the brain, neurotrophin signaling, and Alzheimer's disease: is IGF1-R the common culprit? Neurobiol. Aging, 2008, 29, 795-811.

[89] Lopez-Lopez, C.; Dietrich, M.O.; Metzger, F.; Loetscher, H.; Torres-Aleman, I. Disturbed cross talk between insulin-like growth factor I and AMP-activated protein kinase as a possible cause of vascular dysfunction in the amyloid precursor protein/presenilin 2 mouse model of Alzheimer's disease. J. Neurosci., 2007, 27, 82431.

[90] Iqbal, K.; Liu, F.; Gong, C.X.; Alonso, Adel, C.; Grundke-Iqbal, I. Mechanisms of tau-induced neurodegeneration. Acta Neuropathol., 2009, 118, 53-69.

[91] Lesort, M.; Johnson, G.V. Insulin-like growth factor-1 and insulin mediate transient site-selective increases in tau phosphorylation in primary cortical neurons. Neuroscience, 2000, 99, 305-16.

[92] de la Monte, S.M.; Wands, J.R. Review of insulin and insulin-like growth factor expression, signaling, and malfunction in the central nervous system: relevance to Alzheimer's disease. J. Alzheimers Dis., 2005, 7, 45-61.

[93] Schubert, M.; Gautam, D.; Surjo, D.; Ueki, K.; Baudler, S.; Schubert, D.; Kondo, T.; Alber, J.; Galldiks, N.; Küstermann, E.; Arndt, S.; Jacobs, A.H.; Krone, W.; Kahn, C.R.; Brüning, J.C. Role for neuronal insulin resistance in neurodegenerative diseases. Proc. Natl. Acad. Sci. USA, 2004, 101, 3100-5.

[94] Carro, E.; Torres-Aleman, I. The role of insulin and insulin-like growth factor $\mathrm{I}$ in the molecular and cellular mechanisms underlying the pathology of Alzheimer's disease. Eur. J. Pharmacol., 2004, 490, 127-33.

[95] Craft, S.; Watson, G.S. Insulin and neurodegenerative disease: shared and specific mechanisms. Lancet Neurol., 2004, 3, 169-78.

[96] Gasparini, L.; Xu, H. Potential roles of insulin and IGF-1 in Alzheimer's disease. Trends Neurosci., 2003, 26, 404-6.

[97] Reagan, L.P. Neuronal insulin signal transduction mechanisms in diabetes phenotypes. Neurobiol. Aging, 2005, 26(Suppl 1), 56-9.

[98] Koya, D.; King, G.L. Protein kinase C activation and the development of diabetic complications. Diabetes, 1998, 47, 859-66.

[99] Ishii, H.; Koya, D.; King, G.L. Protein kinase C activation and its role in the development of vascular complications in diabetes mellitus. J. Mol. Med., 1998, 76, 21-31.

[100] Gliki, G.; Wheeler-Jones, C.; Zachary, I. Vascular endothelial growth factor induces protein kinase $\mathrm{C}$ (PKC)-dependent Akt/PKB activation and phosphatidylinositol 3'-kinase-mediates PKC delta phosphorylation: role of PKC in angiogenesis. Cell Biol. Int., 2002, 26, 751-9.

[101] Carmeliet, P.; Storkebaum, E. Vascular and neuronal effects of VEGF in the nervous system: implications for neurological disorders. Semin. Cell Dev. Biol., 2002, 13, 39-53.

[102] Leinninger, G.M.; Vincent, A.M.; Feldman, E.L. The role of growth factors in diabetic peripheral neuropathy. J. Peripher. Nerv. Syst., 2004, 9, 26-53.

[103] Morley, G.K.; Mooradian, A.D.; Levine, A.S.; Morley, J.E. Mechanism of pain in diabetic peripheral neuropathy. Effect of glucose on pain perception in humans. Am. J. Med., 1984, 77, 7982.

[104] Farkas, E.; Luiten, P.G. Cerebral microvascular pathology in aging and Alzheimer's disease. Prog. Neurobiol., 2001, 64, 575-611.
[105] Dyck, P.J.; Karnes, J.L.; O'Brien, P.; Okazaki, H.; Lais, A.; Engelstad, J. The spatial distribution of fiber loss in diabetic polyneuropathy suggests ischemia. Ann. Neurol., 1986, 19, 440-9.

[106] Yasuda, H.; Terada, M.; Maeda, K.; Kogawa, S.; Sanada, M.; Haneda, M.; Kashiwagi, A.; Kikkawa, R. Diabetic neuropathy and nerve regeneration. Prog. Neurobiol., 2003, 69, 229-85.

[107] Nigro, J.; Osman, N.; Dart, A.M.; Little, P.J. Insulin resistance and atherosclerosis. Endocr. Rev., 2006, 27, 242-59.

[108] Cheung, N.; Wong, T.Y. Diabetic retinopathy and systemic vascular complications. Prog. Retin. Eye Res., 2008, 27, 161-76.

[109] Calcutt, N.A.; Tomlinson, D.R.; Willars, G.B.; Keen, P. Axonal transport of substance P-like immunoreactivity in gangliosidetreated diabetic rats. J. Neurol. Sci., 1990, 96, 283-91.

[110] Flyvbjerg, A. Putative pathophysiological role of growth factors and cytokines in experimental diabetic kidney disease. Diabetologia, 2000, 43, 1205-23.

[111] Sheetz, M.J.; King, G.L. Molecular understanding of hyperglycemia's adverse effects for diabetic complications. JAMA, 2002, 288, 2579-88.

[112] Haneda, M.; Koya, D.; Kikkawa, R. Cellular mechanisms in the development and progression of diabetic nephropathy: activation of the DAG-PKC-ERK pathway. Am. J. Kidney Dis., 2001, 38, S17881 .

[113] van Gils, J.M.; Zwaginga, J.J.; Hordijk, P.L. Molecular and functional interactions among monocytes, platelets, and endothelial cells and their relevance for cardiovascular diseases. J. Leukoc. Biol., 2009, 85, 195-204.

[114] Cai, H.; Harrison, D.G. Endothelial dysfunction in cardiovascular diseases: the role of oxidant stress. Circ. Res., 2000, 87, 840-4.

[115] Cersosimo, E.; DeFronzo, R.A. Insulin resistance and endothelial dysfunction: the road map to cardiovascular diseases. Diabetes Metab. Res. Rev., 2006, 22, 423-36.

[116] Rudolph, V.; Freeman, B.A. Cardiovascular consequences when nitric oxide and lipid signaling converge. Circ. Res., 2009, 105, 511-22.

[117] De Rosa, S.; Cirillo, P.; Paglia, A.; Sasso, L.; Di Palma, V.; Chiariello, M. Reactive oxygen species and antioxidants in the pathophysiology of cardiovascular disease: does the actual knowledge justify a clinical approach? Curr. Vasc. Pharmacol., 2010, [Epub ahead of print].

[118] Zeng, G.; Nystrom, F.H.; Ravichandran, L.V.; Cong, L.N.; Kirby, M.; Mostowski, H.; et al. Roles for insulin receptor, PI3-kinase, and Akt in insulin-signaling pathways related to production of nitric oxide in human vascular endothelial cells. Circulation, 2000, 101,1539-45.

[119] Kim, J.A.; Montagnani, M.; Koh, K.K.; Quon, M.J. Reciprocal relationships between insulin resistance and endothelial dysfunction: molecular and pathophysiological mechanisms. Circulation, 2006, 113, 1888-904.

[120] Zhang, H.; Park, Y.; Wu, J.; Chen, X.; Lee, S.; Yang, J.; Dellsperger, K.C.; Zhang, C. Role of TNF-alpha in vascular dysfunction. Clin. Sci. (Lond.), 2009, 116, 219-30.

[121] Calles-Escandon, J.; Cipolla, M. Diabetes and endothelial dysfunction: a clinical perspective. Endocr. Rev., 2001, 22, 36-52.

[122] Barzilaym, J.I.; Freedland, E.S. Inflammation and its relationship to insulin resistance, type 2 diabetes mellitus, and endothelial dysfunction. Metab. Syndr. Relat. Disord., 2003, 1, 55-67.

[123] Dandona, P. Insulin resistance and endothelial dysfunction in atherosclerosis: implications and interventions. Diabetes Technol. Ther., 2002, 4, 809-15.

[124] Cacquevel, M.; Lebeurrier, N.; Cheenne, S.; Vivien, D. Cytokines in neuroinflammation and Alzheimer's disease. Curr. Drug Targets, 2004, 5, 529-34.

[125] Fillit, H.; Ding, W.H.; Buee, L.; Kalmanm J.; Altstiel, L.; Lawlor, B.; Wolf-Klein, G. Elevated circulating tumor necrosis factor levels in Alzheimer's disease. Neurosci. Lett., 1991, 129, 318-20.

[126] Tarkowski, E.; Blennow, K.; Wallin, A.; Tarkowski, A. Intracerebral production of tumor necrosis factor-alpha, a local neuroprotective agent, in Alzheimer disease and vascular dementia. J. Clin. Immunol., 1999, 19, 223-30.

[127] Kaltschmidt, B.; Ndiaye, D.; Korte, M.; Pothion, S.; Arbibe, L.; Prüllage, M.; Pfeiffer, J.; Lindecke, A.; Staiger, V.; Israël, A.; Kaltschmidt, C.; Mémet, S. NF-kappaB regulates spatial memory formation and synaptic plasticity through protein kinase A/CREB signaling. Mol. Cell Biol., 2006, 26, 2936-46. 
[128] Karin, M.; Gallagher, E. TNFR signaling: ubiquitin-conjugated TRAFfic signals control stop-and-go for MAPK signaling complexes. Immunol. Rev., 2009, 228, 225-40.

[129] Patel, J.R.; Brewer, G.J. Age-related changes to tumor necrosis factor receptors affect neuron survival in the presence of betaamyloid. J. Neurosci. Res., 2008, 86, 2303-13.

[130] Perry, R.T.; Collins, J.S.; Wiener, H.; Acton, R.; Go, R.C. The role of TNF and its receptors in Alzheimer's disease. Neurobiol. Aging, 2001, 22, 873-83.

[131] Culpan, D.; Cornish, A.; Love, S.; Kehoe, P.G.; Wilcock, G.K. Protein and gene expression of tumour necrosis factor receptors I and II and their promoter gene polymorphisms in Alzheimer's disease. Exp. Gerontol., 2007, 42, 538-44.

[132] Watson, G.S.; Craft, S. Insulin resistance, inflammation, and cognition in Alzheimer's Disease: lessons for multiple sclerosis. $J$. Neurol. Sci., 2006, 245, 21-33.

[133] Lahiri, D.K.; Chen, D.; Vivien, D.; Ge, Y.W.; Greig, N.H.; Rogers, J.T. Role of cytokines in the gene expression of amyloid betaprotein precursor: identification of a 5'-UTR-binding nuclear factor and its implications in Alzheimer's disease. J. Alzheimers Dis., 2003, 5, 81-90.

[134] Singh, R.; Barden, A.; Mori, T.; Beilin, L. Advanced glycation endproducts: a review. Diabetologia, 2001, 44, 129-46.

[135] Kikuchi, S.; Shinpo, K.; Takeuchi, M.; Yamagishi, S.; Makita, Z.; Sasaki N Tashiro, K. Glycation--a sweet tempter for neuronal death. Brain Res. Brain Res. Rev., 2003, 41, 306-23.

[136] Jakus, V.; Rietbrock, N. Advanced glycation end-products and the progress of diabetic vascular complications. Physiol. Res., 2004, $53,131-42$.

[137] Unoki, H.; Yamagishi, S. Advanced glycation end products and insulin resistance. Curr. Pharm. Des., 2008, 14, 987-9.

[138] Yamagishi, S.; Nakamura K.; Imaizumi, T. Advanced glycation end products (AGEs) and diabetic vascular complications. Curr. Diabetes Rev., 2005, 1, 93-106.

[139] Takeuchi, M.; Kikuchi, S.; Sasaki, N.; Suzuki, T.; Watai, T.; Iwaki, M.; Bucala, R.; Yamagishi, S. Involvement of advanced glycation end-products (AGEs) in Alzheimer's disease. Curr. Alzheimer Res., 2004, $1,39-46$.

[140] Sasaki, N.; Fukatsu, R.; Tsuzuki, K.; Hayashi, Y.; Yoshida, T.; Fujii, N.; Koike, T.; Wakayama, I.; Yanagihara, R.; Garruto, R.; Amano, N.; Makita, Z. Advanced glycation end products in Alzheimer's disease and other neurodegenerative diseases. Am. J. Pathol., 1998, 153, 1149-55.

[141] Smith, M.A.; Sayre, L.M.; Monnier, V.M.; Perry, G. Radical AGEing in Alzheimer's disease. Trends Neurosci., 1995, 18, 172-6.

[142] Cellek, S.; Qu, W.; Schmidt, A.M.; Moncada, S. Synergistic action of advanced glycation end products and endogenous nitric oxide leads to neuronal apoptosis in vitro: a new insight into selective nitrergic neuropathy in diabetes. Diabetologia, 2004, 47, 331-9.

[143] Ramasamy, R.; Vannucci, S.J.; Yan, S.S.; Herold, K.; Yan, S.F.; Schmidt, A.M. Advanced glycation end products and RAGE: a common thread in aging, diabetes, neurodegeneration, and inflammation. Glycobiology, 2005, 15, 16R-28R.

[144] Deane, R.; Sagare, A.; Zlokovic, B.V. The role of the cell surface LRP and soluble LRP in blood-brain barrier Abeta clearance in Alzheimer's disease. Curr. Pharm. Des., 2008, 14, 1601-5.

[145] Cho, H.J.; Son, S.M.; Jin, S.M.; Hong, H.S.; Shin, D.H.; Kim, S.J.; Huh, K.; Mook-Jung, I. RAGE regulates BACE1 and Abeta generation via NFAT1 activation in Alzheimer's disease animal model. FASEB J., 2009, 23, 2639-49.

[146] Grillo, M.A.; Colombatto, S. Advanced glycation end-products (AGEs): involvement in aging and in neurodegenerative diseases. Amino Acids, 2008, 35, 29-36.

[147] Dietschy, J.M.; Turley, S.D. Cholesterol metabolism in the brain. Curr. Opin. Lipidol., 2001, 12, 105-12.

[148] Tabas, I. Consequences of cellular cholesterol accumulation: basic concepts and physiological implications. J. Clin. Invest., 2002, 110, 905-11.

[149] Bloch, K. The biological synthesis of cholesterol. Science, 1965, $150,19-28$.

[150] Vance, J.E.; Hayashi, H.; Karten, B. Cholesterol homeostasis in neurons and glial cells. Semin. Cell Dev. Biol., 2005, 16, 193-212.

[151] Herz, J.; Bock, H.H. Lipoprotein receptors in the nervous system. Annu. Rev. Biochem., 2002, 71, 405-34.

[152] Canevari, L.; Clark, JB. Alzheimer's disease and cholesterol: the fat connection. Neurochem. Res., 2007, 32, 739-50.
[153] Grimm, M.O.; Grimm, H.S.; Tomic, I.; Beyreuther, K.; Hartmann, T.; Bergmann, C. Independent inhibition of Alzheimer disease beta- and gamma-secretase cleavage by lowered cholesterol levels. J. Biol. Chem., 2008, 283, 11302-11.

[154] Burns, M. ; Duff, K. Cholesterol in Alzheimer's disease and tauopathy. Ann. N.Y. Acad. Sci., 2002, 977, 367-75.

[155] Wolozin, B.; Manger, J.; Bryant, R.; Cordy, J.; Green, R.C.; McKee, A. Re-assessing the relationship between cholesterol, statins and Alzheimer's disease. Acta. Neurol. Scand. Suppl., 2006, $185,63-70$.

[156] Bjorkhem, I.; Meaney, S. Brain cholesterol: long secret life behind a barrier. Arterioscler. Thromb. Vasc. Biol., 2004, 24, 806-15.

[157] Wollmer, M.A.; Streffer, J.R.; Lutjohann, D.; Tsolaki, M.; Iakovidou, V.; Hegi, T.; Pasch, T.; Jung, H.H.; Bergmann, K.; Nitsch, R.M.; Hock, C.; Papassotiropoulos, A. ABCA1 modulates CSF cholesterol levels and influences the age at onset of Alzheimer's disease. Neurobiol. Aging, 2003, 24, 421-6.

[158] Kolsch, H.; Lutjohann, D.; von Bergmann, K.; Heun, R. The role of 24S-hydroxycholesterol in Alzheimer's disease. J. Nutr. Health Aging, 2003, 7, 37-41.

[159] Lutjohann, D. Cholesterol metabolism in the brain: importance of 24S-hydroxylation. Acta. Neurol. Scand. Suppl., 2006, 185, 33-42.

[160] Lukiw, W.J.; Pappolla, M.; Pelaez, R.P.; Bazan, N.G. Alzheimer's disease--a dysfunction in cholesterol and lipid metabolism. Cell Mol. Neurobiol., 2005, 25, 475-83.

[161] Desai, P.; DeKosky, S.T.; Kamboh, M.I. Genetic variation in the cholesterol 24-hydroxylase (CYP46) gene and the risk of Alzheimer's disease. Neurosci. Lett., 2002, 328, 9-12.

[162] Lutjohann, D.; von Bergmann, K. 24S-hydroxycholesterol: a marker of brain cholesterol metabolism. Pharmacopsychiatry, 2003, 36 Suppl 2, S102-6.

[163] Wolozin, B. Cyp46 (24S-cholesterol hydroxylase): a genetic risk factor for Alzheimer disease. Arch. Neurol., 2003, 60, 16-8.

[164] Cedazo-Minguez, A. Apolipoprotein E and Alzheimer's disease: molecular mechanisms and therapeutic opportunities. J. Cell Mol. Med., 2007, 11,1227-38.

[165] Rebeck, G.W.; Kindy, M.; LaDu, M.J. Apolipoprotein E and Alzheimer's disease: the protective effects of ApoE2 and E3. $J$. Alzheimers. Dis., 2002, 4, 145-54.

[166] Huang, Y. Apolipoprotein E and Alzheimer disease. Neurology, 2006, 66, S79-85.

[167] Saunders, A.M.; Strittmatter, W.J.; Schmechel, D.; George-Hyslop, P.H.; Pericak-Vance, M.A.; Joo, S.H.; Rosi, B.L.; Gusella, J.F.; Crapper-Maclachlan, D.R.; Alberts, M.J.; Hulette, C.; Crain, B.; Goldgeber, D.; Roses, A.D. Association of apolipoprotein E allele epsilon 4 with late-onset familial and sporadic Alzheimer's disease. Neurology, 1993, 43, 1467-72.

[168] Mahley, R.W.; Weisgraber, K.H.; Huang, Y. Apolipoprotein E4: a causative factor and therapeutic target in neuropathology, including Alzheimer's disease. Proc. Natl. Acad. Sci. USA, 2006, 103, 564451.

[169] Rahman, A.; Akterin, S.; Flores-Morales, A.; Crisby, M.; Kivipelto, M.; Schultzberg, M.; Cedazo-Mínguez, A. High cholesterol diet induces tau hyperphosphorylation in apolipoprotein E deficient mice. FEBS Lett., 2005, 579, 6411-6.

[170] Grimm, M.O.; Grimm, H.S.; Hartmann, T. Amyloid beta as a regulator of lipid homeostasis. Trends Mol. Med., 2007, 13, 337-44.

[171] Hartmann, T.; Kuchenbecker, J.; Grimm, M.O. Alzheimer's disease: the lipid connection. J. Neurochem., 2007, 103(Suppl 1), 159-70.

[172] Wolozin, B. A fluid connection: cholesterol and Abeta. Proc. Natl. Acad. Sci. USA, 2001, 98, 5371-3.

[173] Chauhan, N.B. Membrane dynamics, cholesterol homeostasis, and Alzheimer's disease. J. Lipid Res., 2003, 44, 2019-29.

[174] Shobab, L.A.; Hsiung, G.Y.; Feldman, H.H. Cholesterol in Alzheimer's disease. Lancet Neurol., 2005, 4, 841-52.

[175] Refolo, L.M.; Malester, B.; LaFrancois, J.; Bryant-Thomas, T.; Wang, R.; Tint, G.S.; Sambamurti, K.; Duff, K.; Pappolla, M.A. Hypercholesterolemia accelerates the Alzheimer's amyloid pathology in a transgenic mouse model. Neurobiol. Dis., 2000, 7, 321-31.

[176] Simons, M.; Keller, P.; Dichgans, J.; Schulz, J.B. Cholesterol and Alzheimer's disease: is there a link? Neurology, 2001, 57, 1089-93.

[177] Eckert, G.P.; Kirsch, C.; Muller, W.E. Brain-membrane cholesterol in Alzheimer's disease. J. Nutr. Health Aging, 2003, 7, 18-23. 
[178] Li, G.; Shofer, J.B.; Kukull, W.A.; Peskind, E.R.; Tsuang, D.W.; Breitner, J.C.; McCormick, W.; Bowen, J.D.; Teri, L.; Schellenberg, G.D.; Larson, E.B. Serum cholesterol and risk of Alzheimer disease: a community-based cohort study. Neurology, 2005, 65, 1045-50.

[179] Wellington, C.L. Cholesterol at the crossroads: Alzheimer's disease and lipid metabolism. Clin. Genet., 2004, 66, 1-16.

[180] Lane, R.M.; Farlow, M.R. Lipid homeostasis and apolipoprotein E in the development and progression of Alzheimer's disease. J. Lipid Res., 2005, 46, 949-68.

[181] Poirier, J. Apolipoprotein E, cholesterol transport and synthesis in sporadic Alzheimer's disease. Neurobiol. Aging, 2005, 26, 355-61.

[182] Bell, R.D.; Sagare, A.P.; Friedman, A.E.; Bedi, G.S.; Holtzman, D.M.; Deane, R.; Zlokovic, B.V. Transport pathways for clearance of human Alzheimer's amyloid beta-peptide and apolipoproteins E and $\mathrm{J}$ in the mouse central nervous system. J. Cereb. Blood Flow Metab., 2007, 27, 909-18.

[183] Dechant, G.; Neumann, H. Neurotrophins. Adv. Exp. Med. Biol., 2002, 513, 303-34.

[184] Hennigan, A.; O'Callaghan, R.M.; Kelly, A.M. Neurotrophins and their receptors: roles in plasticity, neurodegeneration and neuroprotection. Biochem. Soc. Trans., 2007, 35, 424-7.

[185] Huang, E.J.; Reichardt, L.F. Neurotrophins: roles in neuronal development and function. Annu. Rev. Neurosci., 2001, 24, 677736.

[186] von Schack, D.; Casademunt, E.; Schweigreiter, R.; Meyer, M.; Bibel, M.; Dechant, G. Complete ablation of the neurotrophin receptor p75NTR causes defects both in the nervous and the vascular system. Nat. Neurosci., 2001, 4, 977-8.

[187] Crowley, C.; Spencer, S.D.; Nishimura, M.C.; Chen, K.S.; PittsMeek, S.; Armanini, M.P.; Ling, L.H.; McMahon, S.B.; Shelton, D.L.; Levinson, A.D.; Phillips, H.S. Mice lacking nerve growth factor display perinatal loss of sensory and sympathetic neurons yet develop basal forebrain cholinergic neurons. Cell, 1994, 76, 100111 .

[188] Kiriazis, H.; Du, X.J.; Feng, X.; Hotchkin, E.; Marshall, T.; Finch, S.; Gao, X.M.; Lambert, G.; Choate, J.K.; Kaye, D.M. Preserved left ventricular structure and function in mice with cardiac sympathetic hyperinnervation. Am. J. Physiol. Heart Circ. Physiol., 2005, 289, H1359-65.

[189] Glebova, N.O.; Ginty, D.D. Heterogeneous requirement of NGF for sympathetic target innervation in vivo. J. Neurosci., 2004, 24, 74351.

[190] Cao, J.M.; Chen, L.S.; KenKnight, B.H.; Ohara, T.; Lee, M.H.; Tsai, J.; Lai, W.W.; Karagueuzian, H.S.; Wolf, P.L.; Fishbein, M.C.; Chen, P.S. Nerve sprouting and sudden cardiac death. Circ. Res., 2000, 86, 816-21.

[191] Lockhart, S.T.; Turrigiano, G.G.; Birren, S.J. Nerve growth factor modulates synaptic transmission between sympathetic neurons and cardiac myocytes. J. Neurosci., 1997, 17, 9573-82.

[192] Qin, F.; Vulapalli, R.S.; Stevens, S.Y.; Liang, C.S. Loss of cardiac sympathetic neurotransmitters in heart failure and NE infusion is associated with reduced NGF. Am. J. Physiol. Heart Circ. Physiol., 2002, 282, H363-71.

[193] Hempstead, B.L. Sculpting organ innervation. J. Clin. Invest., 2004, 113, 811-3.

[194] Dechant, G.; Barde, Y.A. The neurotrophin receptor p75(NTR): novel functions and implications for diseases of the nervous system. Nat. Neurosci., 2002, 5, 1131-6.

[195] Kohn, J.; Aloyz, R.S.; Toma, J.G.; Haak-Frendscho, M.; Miller, F.D. Functionally antagonistic interactions between the TrkA and p75 neurotrophin receptors regulate sympathetic neuron growth and target innervation. J. Neurosci., 1999, 19, 5393-408.

[196] Huang, E.J.; Reichardt, L.F. Trk receptors: roles in neuronal signal transduction. Annu. Rev. Biochem., 2003, 72, 609-42.

[197] Hassankhani, A.; Steinhelper, M.E.; Soonpaa, M.H.; Katz, E.B.; Taylor, D.A.; Andrade-Rozental, A.; Factor, S.M.; Steinberg, J.J.; Field, L.J.; Federoff, H.J. Overexpression of NGF within the heart of transgenic mice causes hyperinnervation, cardiac enlargement, and hyperplasia of ectopic cells. Dev. Biol., 1995, 169, 309-21.

[198] Yang, L.L.; Gros, R.; Kabir, M.G.; Sadi, A.; Gotlieb, A.I.; Husain, M.; Stewart, D.J. Conditional cardiac overexpression of endothelin1 induces inflammation and dilated cardiomyopathy in mice. Circulation, 2004, 109, 255-61.

[199] Ieda, M.; Fukuda, K.; Hisaka, Y.; Kimura, K.; Kawaguchi, H.; Fujita, J.; Shimoda, K.; Takeshita, E.; Okano, H.; Kurihara, Y.;
Kurihara, H.; Ishida, J.; Fukamizu, A.; Federoff, H.J.; Ogawa, S. Endothelin-1 regulates cardiac sympathetic innervation in the rodent heart by controlling nerve growth factor expression. J. Clin. Invest., 2004, 113, 876-84.

[200] Kaye, D.M.; Vaddadi, G.; Gruskin, S.L.; Du, X.J.; Esler, M.D. Reduced myocardial nerve growth factor expression in human and experimental heart failure. Circ. Res., 2000, 86, E80-4.

[201] Schulte-Herbruggen, O.; Jockers-Scherubl, M.C.; Hellweg, R. Neurotrophins: from pathophysiology to treatment in Alzheimer's disease. Curr. Alzheimer Res., 2008, 5, 38-44.

[202] Dawbarn, D.; Allen, S.J. Neurotrophins and neurodegeneration. Neuropathol. Appl. Neurobiol., 2003, 29, 211-30.

[203] Durbeej, M.; Soderstrom, S.; Ebendal, T.; Birchmeier, C.; Ekblom, P. Differential expression of neurotrophin receptors during renal development. Development, 1993, 119, 977-89.

[204] Sariola, H.; Saarma, M.; Sainio, K.; Arumae, U.; Palgi, J.; Vaahtokari, A.; Thesleff, I.; Karavanq, A. et al. Dependence of kidney morphogenesis on the expression of nerve growth factor receptor. Science, 1991, 254, 571-3.

[205] Bonofiglio, R.; Antonucci, M.T.; Papalia, T.; Romeo, F.; Capocasale, G.; Caroleo, M.C.; Di Fausto, V.; Aloe, L. Nerve growth factor (NGF) and NGF-receptor expression in diseased human kidneys. J. Nephrol., 2007, 20, 186-95.

[206] Alpers, C.E.; Hudkins, K.L.; Ferguson, M.; Johnson, R.J.; Schatteman, G.C.; Bothwell, M. Nerve growth factor receptor expression in fetal, mature, and diseased human kidneys. $L a b$. Invest., 1993, 69, 703-13.

[207] Sadowski, M.; Pankiewicz, J.; Scholtzova, H.; Li, Y.S.; Quartermain, D.; Duff, K.; Wisniewski, T. Links between the pathology of Alzheimer's disease and vascular dementia. Neurochem. Res., 2004, 29, 1257-66.

[208] Kalaria, R.N.; Ballard, C. Overlap between pathology of Alzheimer disease and vascular dementia. Alzheimer Dis. Assoc. Disord., 1999, 13(Suppl 3), S115-23.

[209] Gorelick, P.B. Risk factors for vascular dementia and Alzheimer disease. Stroke, 2004, 35, 2620-2.

[210] Mungas, D.; Reed, B.R.; Ellis, W.G.; Jagust, W.J. The effects of age on rate of progression of Alzheimer disease and dementia with associated cerebrovascular disease. Arch. Neurol., 2001, 58, 1243 7.

[211] Schnell, O.; Standl, E. Impaired glucose tolerance, diabetes, and cardiovascular disease. Endocr. Pract., 2006, 12(Suppl 1), 16-9.

[212] Sowers, J.R.; Epstein, M.; Frohlich, E.D. Diabetes, hypertension, and cardiovascular disease: an update. Hypertension, 2001, 37, 1053-9.

[213] Martins, I.J.; Hone, E.; Foster, J.K.; Sunram-Lea, S.I.; Gnjec, A.; Fuller, S.J.; Nolan, D.; Gandy, S.E.; Martins, R.N. Apolipoprotein $\mathrm{E}$, cholesterol metabolism, diabetes, and the convergence of risk factors for Alzheimer's disease and cardiovascular disease. Mol. Psychiatry, 2006, 11, 721-36.

[214] Coker, L.H.; Shumaker, S.A. Type 2 diabetes mellitus and cognition: an understudied issue in women's health. J. Psychosom. Res., 2003, 54, 129-39.

[215] Furie, K.; Inzucchi, S.E. Diabetes mellitus, insulin resistance, hyperglycemia, and stroke. Curr. Neurol. Neurosci. Rep., 2008, 8, 12-9.

[216] Janson, J.; Laedtke, T.; Parisi, J.E.; O'Brien, P.; Petersen, R.C.; Butler, P.C. Increased risk of type 2 diabetes in Alzheimer disease. Diabetes, 2004, 53, 474-81.

[217] Knopman, D.S. Dementia and cerebrovascular disease. Mayo Clin. Proc., 2006, 81, 223-30.

[218] Iadecola, C.; Gorelick, P.B. Converging pathogenic mechanisms in vascular and neurodegenerative dementia. Stroke, 2003, 34, 335-7.

[219] Stewart, R.; Xue, Q.L.; Masaki, K.; Petrovitch, H.; Ross, G.W.; White, L.R.; Launer, L.J. Change in blood pressure and incident dementia: a 32-year prospective study. Hypertension, 2009, 54, 233-40.

[220] Roman, G.C. Vascular dementia may be the most common form of dementia in the elderly. J. Neurol. Sci., 2002, 203-204:7-10.

[221] Grundy, S.M.; Benjamin, I.J.; Burke, G.L.; Chait, A.; Eckel, R.H.; Howard, B.V.; Mitch, W.; Smith, S.C. Jr.; Sowers, J.R. Diabetes and cardiovascular disease: a statement for healthcare professionals from the American Heart Association. Circulation, 1999, 100, 1134-46. 
[222] Prince, M.J. Vascular risk factors and atherosclerosis as risk factors for cognitive decline and dementia. J. Psychosom. Res., 1995, 39, 525-30.

[223] van Oijen, M.; de Jong, F.J.; Witteman, J.C.; Hofman, A.; Koudstaal, P.J.; Breteler, M.M. Atherosclerosis and risk for dementia. Ann. Neurol., 2007, 61, 403-10.

[224] Edbauer, D.; Willem, M.; Lammich, S.; Steiner, H.; Haass, C. Insulin-degrading enzyme rapidly removes the beta-amyloid precursor protein intracellular domain (AICD). J. Biol. Chem., 2002, 277, 13389-93.

[225] Authier, F.; Posner, B.I.; Bergeron, J.J. Insulin-degrading enzyme. Clin. Invest. Med., 1996, 19, 149-60.

[226] Vekrellis, K.; Ye, Z.; Qiu, W.Q.; Walsh, D.; Hartley, D.; Chesneau, V.; Rosner, M.R.; Selkoe, D.J. Neurons regulate extracellular levels of amyloid beta-protein via proteolysis by insulin-degrading enzyme. J. Neurosci., 2000, 20, 1657-65.

[227] Hughes, S.R.; Khorkova, O.; Goyal, S.; Knaeblein, J.; Heroux, J.; Riedel, N.G.; Sahasrabudhe, S. Alpha2-macroglobulin associates with beta-amyloid peptide and prevents fibril formation. Proc. Natl. Acad. Sci. USA, 1998, 95, 3275-80.

[228] Kurochkin, I.V.; Goto, S. Alzheimer's beta-amyloid peptide specifically interacts with and is degraded by insulin degrading enzyme. FEBS Lett., 1994, 345, 33-7.

[229] Sagare, A.; Deane, R.; Bell, R.D.; Johnson, B.; Hamm, K.; Pendu, R.; Marky, A.; Lenting, P.J.; Wu, Z.; Zarcone, T.; Goate, A.; Mayo, K.; Perlmutter, D.; Coma, M.; Zhong, Z.; Zlokovic, B.V. Clearance of amyloid-beta by circulating lipoprotein receptors. Nat. Med., 2007, 13,1029-31.

[230] Qiu, W.Q.; Walsh, D.M.; Ye, Z.; Vekrellis, K.; Zhang, J.; Podlisny, M.B.; Rosner, M.R.; Safavi, A.; Hersh, L.B.; Selkoe, D.J. Insulindegrading enzyme regulates extracellular levels of amyloid betaprotein by degradation. J. Biol. Chem., 1998, 273, 32730-8.

[231] Farris, W.; Mansourian, S.; Chang, Y.; Lindsley, L.; Eckman, E.A.; Frosch, M.P.; Eckman, C.B.; Tanzi, R.E.; Selkoe, D.J.; Guenette, S. Insulin-degrading enzyme regulates the levels of insulin, amyloid beta-protein, and the beta-amyloid precursor protein intracellular domain in vivo. Proc. Natl. Acad. Sci. USA, 2003, 100, 4162-7.

[232] Deane, R.; Bell, R.D.; Sagare, A.; Zlokovic, B.V. Clearance of amyloid-beta peptide across the blood-brain barrier: implication for therapies in Alzheimer's disease. CNS Neurol. Disord. Drug Targets, 2009, 8, 16-30.

[233] Casserly, I.; Topol, E. Convergence of atherosclerosis and Alzheimer's disease: inflammation, cholesterol, and misfolded proteins. Lancet, 2004, 363, 1139-46.

[234] Puglielli, L.; Konopka, G.; Pack-Chung, E.; Ingano, L.A.; Berezovska, O.; Hyman, B.T.; Chang, T.Y.; Tanzi, R.E.; Kovacs,
D.M. Acyl-coenzyme A: cholesterol acyltransferase modulates the generation of the amyloid beta-peptide. Nat. Cell Biol., 2001, 3, 905-12.

[235] Huttunen, H.J.; Greco, C.; Kovacs, D.M. Knockdown of ACAT-1 reduces amyloidogenic processing of APP. FEBS Lett., 2007, 581,1688-92.

[236] Hutter-Paier, B.; Huttunen, H.J.; Puglielli, L.; Eckman, C.B.; Kim, D.Y.; Hofmeister, A.; Moir, R.D.; Domnitz, S.B.; Frosch, M.P.; Windisch, M.; Kovacs, D.M. The ACAT inhibitor CP-113,818 markedly reduces amyloid pathology in a mouse model of Alzheimer's disease. Neuron, 2004, 44, 227-38.

[237] Jick, H.; Zornberg, G.L.; Jick, S.S.; Seshadri, S.; Drachman, D.A. Statins and the risk of dementia. Lancet, 2000, 356, 1627-31.

[238] Menge, T.; Hartung, H.P.; Stuve, O. Statins--a cure-all for the brain? Nat. Rev. Neurosci., 2005, 6, 325-31.

[239] Wolozin, B.; Brown, J.; 3rd, Theisler, C.; Silberman, S. The cellular biochemistry of cholesterol and statins: insights into the pathophysiology and therapy of Alzheimer's disease. CNS Drug Rev., 2004, 10, 127-46.

[240] Zandi, P.P.; Sparks, D.L.; Khachaturian, A.S.; Tschanz, J.; Norton, M.; Steinberg, M.; Welsh-Bohmer, K.A.; Breitner, J.C.; The Cache County Study Investigations. Do statins reduce risk of incident dementia and Alzheimer disease? The Cache County Study. Arch. Gen. Psychiatry, 2005, 62, 217-24.

[241] Hartman, T. Cholesterol and Alzheimer's disease: statins, cholesterol depletion in APP processing and Abeta generation. Subcell Biochem., 2005, 38, 365-80.

[242] Reid, P.C.; Urano, Y.; Kodama, T.; Hamakubo, T. Alzheimer's disease: cholesterol, membrane rafts, isoprenoids and statins. $J$ Cell Mol. Med., 2007, 11, 383-92.

[243] Kirsch, C.; Eckert, G.P.; Koudinov, A.R.; Muller, W.E. Brain cholesterol, statins and Alzheimer's Disease. Pharmacopsychiatry, 2003, 36(Suppl 2), S113-9.

[244] Zamrini, E.; McGwin, G.; Roseman, J.M. Association between statin use and Alzheimer's disease. Neuroepidemiology, 2004, 23, 94-8.

[245] Akomolafe, A.; Beiser, A.; Meigs, J.B.; Au, R.; Green, R.C.; Farrer, L.A.; Wolf, P.A.; Seshadri, S. Diabetes mellitus and risk of developing Alzheimer disease: results from the Framingham Study. Arch. Neurol., 2006, 63, 1551-5.

[246] Heese, K.; Low, J.W.; Inoue, N. Nerve growth factor, neural stem cells and Alzheimer's disease. Neurosignals, 2006, 15, 1-12.

[247] van den Berg, E.; Kessels, R.P.; Kappelle, L.J.; de Haan, E.H.; Biessels, G.J. Type 2 diabetes, cognitive function and dementia: vascular and metabolic determinants. Drugs Today (Barc), 2006, $42,741-54$.

(C) Kumari and Heese; Licensee Bentham Open.

This is an open access article licensed under the terms of the Creative Commons Attribution Non-Commercial License (http://creativecommons.org/licenses/by-nc/3.0/) which permits unrestricted, non-commercial use, distribution and reproduction in any medium, provided the work is properly cited. 